\title{
Effects of Process and Formulation Parameters on Submicron Polymeric Particles Produced by a Rapid Emulsion-Diffusion Method
}

\author{
Clara Luisa Domínguez-Delgado*D, Zubia Akhtar, Godfrey Awuah-Mensah, Braden Wu \\ and Hugh David Charles Smyth *
}

Citation: Domínguez-Delgado, C.L.; Akhtar, Z.; Awuah-Mensah, G.; Wu, B.; Smyth, H.D.C. Effects of Process and Formulation Parameters on Submicron Polymeric Particles Produced by a Rapid EmulsionDiffusion Method. Nanomaterials 2022, 12, 229. https://doi.org/ $10.3390 /$ nano12020229

Academic Editors: Helena

P. Felgueiras and

Henrich Frielinghaus

Received: 19 November 2021

Accepted: 4 January 2022

Published: 11 January 2022

Publisher's Note: MDPI stays neutral with regard to jurisdictional claims in published maps and institutional affiliations.

Copyright: (C) 2022 by the authors. Licensee MDPI, Basel, Switzerland. This article is an open access article distributed under the terms and conditions of the Creative Commons Attribution (CC BY) license (https:// creativecommons.org/licenses/by/ $4.0 /)$.
Division of Molecular Pharmaceutics and Drug Delivery, College of Pharmacy, The University of Texas at Austin 2409 University Avenue, Austin, TX 78712, USA; zubiaakhtar@utexas.edu (Z.A.); gamensah@utexas.edu (G.A.-M.); braden.s.wu@gmail.com (B.W.)

* Correspondence: claraldominguezd@gmail.com (C.L.D.-D.); hugh.smyth@austin.utexas.edu (H.D.C.S.); Tel.: +52-553-489-9461 (C.L.D.-D.); +1-512-471-3383 (H.D.C.S.)

\begin{abstract}
Emulsification-diffusion method is often used to produce polymeric nanoparticles. However, their numerous and/or lengthy steps make it difficult to use widely. Thus, a modified method using solvent blends (miscible/partially miscible in water, 25-100\%) as the organic phases to overcome these disadvantages and its design space were investigated. To further simplify the process, no organic/aqueous phase saturation and no water addition after the emulsification step were performed. Biodegradable (PLGA) or $\mathrm{pH}$-sensitive (Eudragit ${ }^{\circledR}$ E100) nanoparticles were robustly produced using low /medium shear stirring adding dropwise the organic phase into the aqueous phase or vice versa. Several behaviors were also obtained: lowering the partially water-miscible solvent ratio relative to the organic phase or the poloxamer-407 concentration; or increasing the organic phase polarity or the polyvinyl alcohol concentration produced smaller particle sizes/polydispersity. Nanoparticle zeta potential increased as the water-miscible solvent ratio increased. Poloxamer- 407 showed better performance to decrease the particle size $(\sim 50 \mathrm{~nm})$ at low concentrations $(\leq 1 \%, w / v)$ compared with polyvinyl alcohol at $1-5 \%(w / v)$, but higher concentrations produced bigger particles/polydispersity $(\geq 600 \mathrm{~nm})$. Most important, an inverse linear correlation to predict the particle size by determining the solubility parameter was found. A rapid method to broadly prepare nanoparticles using straightforward equipment is provided.
\end{abstract}

Keywords: $\mathrm{pH}$-sensitive nanoparticles; rapid emulsification-diffusion; solubility parameter correlation; Eudragit ${ }^{\circledR}$ E100; PLGA; biodegradable nanoparticles

\section{Introduction}

Emulsification-solvent diffusion method is able to produce polymeric nanoparticles (NPs) with high yields, no need of high shear stirring or ultrasonication, batch-to-batch reproducibility and good encapsulation efficiencies [1,2]. However, numerous and long steps involved to pre-saturate the solvents and to eliminate higher volumes of water from the final dispersion make it difficult to use as a feasible method for many applications. Moreover, the tunability or range of particles sizes produced from the few partially miscible solvents is limited [3]. Thus, modifications of this method are proposed in an attempt to overcome those disadvantages. Additionally, the seeking of simple, eco-friendly, safe and scalable methods to produce NPs are more often required in the pharmaceutical field.

Biomedical applications of polymeric NPs have been growing, especially in recent years due to their multifunctional properties [4]. Generally, methods to produce NPs involve two main strategies, the use of preformed polymers or the polymerization process using monomers [5]. Preformed polymers are preferred because of the low toxicity compared 
with the polymerization techniques [3,6]. The "top-down" method for producing polymeric nanoparticles includes solvent emulsification-evaporation, solvent emulsificationdiffusion, coacervation, and nanoprecipitation (solvent displacement method) [2,5].

In the standard emulsification-diffusion method, an $\mathrm{o} / \mathrm{w}$ emulsion is formed using a partially water-miscible solvent previously saturated with water at room temperature to ensure the initial thermodynamic equilibrium of both liquids. This organic phase (OP), containing the polymer and the drug, is emulsified with an aqueous phase (AP) previously saturated with the organic solvent, containing a surfactant. The subsequent dilution with water induces the solvent diffusion from the droplets to the external phase, resulting in the formation of NPs. The solvent is then removed by evaporation or filtration [1]. This method was based on the emulsification-evaporation method in which non watermiscible solvents (generally, dichloromethane and chloroform) are used to prepare an emulsion with the subsequent solvent removal [7]. However, in order to use less toxic solvents and low shear stirring, the emulsification-diffusion method was further developed. Several modifications of this method have been achieved (Table 1) skipping or adding some steps [8], changing operating conditions in some steps [9], using different organic solvents [10-12], and replacing mixing techniques [13-15]. Similar modifications to the emulsification-solvent evaporation method have also been reported [16-18]. All these modifications have been performed in an attempt to provide new and better alternatives to produce NPs. Nevertheless, the use of toxic solvents (Class I) [19] and several as long steps are still involved in the processes.

In this study, the emulsion-diffusion method was modified to produce $\mathrm{pH}$-sensitive polymeric or biodegradable NPs by using solvent blends as organic phases (OPs), consisting of partially water-miscible solvents and water-miscible solvents at ratios from 25 to $100 \%$. Solvents Class 3 (low toxicity) [19] were used in this study. No previous solvents saturation and no water addition after the emulsification step were done, reducing the steps and consequently the time of NPs processing using simple equipment. Two polymers (Eudragit ${ }^{\circledR}$ E100 and PLGA 85:15 and 50:50) and two stabilizers, poloxamer-407 (P-407) and polyvinyl alcohol (PVA), were chosen for their safety $[20,21]$ and used varying their concentrations. NPs average size, polydispersity index (PdI), zeta potential and $\mathrm{pH}$ analysis were determined to evaluate the influence of the formulation and operating parameters. Surface-response plots to analyze the design space of the method were built. More importantly, a linear correlation to predict the particle size in the final aqueous phase from the Hansen solubility parameters of the organic solvent blends was investigated. These studies were performed since the particle dispersibility [22,23], transmittance [24] or particle sizes have only been studied in organic solvents [25] from the Hansen solubility parameters.

Table 1. Steps of the emulsion-diffusion method modifications.

\begin{tabular}{|c|c|c|c|c|c|c|c|}
\hline \multirow[b]{2}{*}{ Solvent Type of OP } & \multirow[b]{2}{*}{ Saturation } & \multicolumn{3}{|c|}{ Emulsification } & \multirow[b]{2}{*}{$\begin{array}{l}\text { Dilution } \\
\text { (Water) }\end{array}$} & \multirow[b]{2}{*}{ EVP } & \multirow[b]{2}{*}{ NP Type/Ref. } \\
\hline & & $\begin{array}{c}\text { Phases } \\
\text { Addition }\end{array}$ & Mixing & $\mathbf{S}$ & & & \\
\hline \multicolumn{8}{|c|}{ Standard emulsification-diffusion method } \\
\hline Partially water-miscible solvents & + & $\mathrm{OP} \rightarrow \mathrm{AP}$ & High-shear stirring & + & + & $+/ \mathrm{F}$ & NSP [1] \\
\hline \multicolumn{8}{|c|}{ Modifications of the emulsification-diffusion method } \\
\hline Partially water-miscible solvents & + & $\mathrm{OP} \rightarrow \mathrm{AP}$ & Low/high shear stirring & + & - & + & NSP [8] \\
\hline Partially water-miscible solvents & $+\left(47^{\circ} \mathrm{C}\right)$ & $\mathrm{OP} \rightarrow \mathrm{AP}$ & $\begin{array}{l}\text { High-shear stirring } \\
\left(47 \pm 2{ }^{\circ} \mathrm{C}\right)\end{array}$ & + & + & + & SLN [9] \\
\hline $\begin{array}{l}\text { Miscible, non-miscible and } \\
\text { partially miscible solvents in } \\
\text { water (individual or combined) }\end{array}$ & - & $\begin{array}{c}\mathrm{OP} \rightarrow \mathrm{AP} \\
(\mathrm{AP}: \\
\text { glucose-ACE })\end{array}$ & $\begin{array}{l}\text { Pre-stirring }(1000 \mathrm{rpm} / 3 \mathrm{~h}) \\
\text { High-shear stirring } \\
(15,000 \mathrm{rpm} / 5 \mathrm{~min})\end{array}$ & + & + & + & NSP [11] \\
\hline Partially water-miscible solvent & - & $\mathrm{OP} \rightarrow \mathrm{AP}$ & $\begin{array}{l}\text { Pre-stirring }(3 \mathrm{~h}) \\
\text { High-shear stirring } \\
(15,000 \mathrm{rpm} / 5 \mathrm{~min})\end{array}$ & + & $\begin{array}{c}+ \text { (water } \\
\text { bath } \\
\left.40^{\circ} \mathrm{C}\right)\end{array}$ & + & $\begin{array}{l}{[10]} \\
\text { NSP }\end{array}$ \\
\hline
\end{tabular}


Table 1. Cont.

\begin{tabular}{|c|c|c|c|c|c|c|c|}
\hline \multirow[b]{2}{*}{ Solvent Type of OP } & \multirow[b]{2}{*}{ Saturation } & \multicolumn{3}{|c|}{ Emulsification } & \multirow[b]{2}{*}{$\begin{array}{l}\text { Dilution } \\
\text { (Water) }\end{array}$} & \multirow[b]{2}{*}{ EVP } & \multirow[b]{2}{*}{ NP Type/Ref. } \\
\hline & & $\begin{array}{l}\text { Phases } \\
\text { Addition }\end{array}$ & Mixing & $\mathbf{S}$ & & & \\
\hline Partially water-miscible solvent & - & $\mathrm{OP} \rightarrow \mathrm{AP}$ & $\begin{array}{c}\text { Pre-stirring }(1000 \mathrm{rpm} / \\
20 \mathrm{~min}) \rightarrow \text { High-shear } \\
\text { stirring }(10,000-15,000 \mathrm{rpm}) \\
\text { or Sonication }(60 \% \\
\text { amplitude } / 1 \mathrm{~min})\end{array}$ & + & + & + & NSP [12] \\
\hline Partially water-miscible solvent & + & $\mathrm{OP} \rightarrow \mathrm{AP}$ & Ultrasound (2 min), ice bath & + & + & $+\left(40^{\circ} \mathrm{C}\right)$ & $\mathrm{NC}[13]$ \\
\hline $\begin{array}{l}\text { Two organic phases: } \\
\text { 1. Partially water-miscible } \\
\text { gas + drug/ } \\
\text { 2. Water-miscible } \\
\text { solvent + polymer }\end{array}$ & - & $\begin{array}{c}\text { Two steps: } \\
\begin{array}{c}1=\mathrm{OP}_{1} \rightarrow \mathrm{OP}_{2} \\
2=\mathrm{OP}_{2} \rightarrow \mathrm{AP} \\
2 \mathrm{~mL} / \mathrm{min}\end{array}\end{array}$ & Magnetic stirring & + & + & $\begin{array}{c}+ \\
(3 \mathrm{~h})\end{array}$ & $\begin{array}{l}\mathrm{NC} \\
{[14]}\end{array}$ \\
\hline Partially water-miscible solvent & - & $\mathrm{AP} \rightarrow \mathrm{OP}$ & Magnetic stirring & - & - & C & MCP [15] \\
\hline \multicolumn{8}{|c|}{ Modifications of the emulsification-solvent evaporation method } \\
\hline $\begin{array}{l}\text { Partially miscible or non-miscible } \\
\text { solvents in water }\end{array}$ & - & $\mathrm{OP} \rightarrow \mathrm{AP}$ & Ultrasound (55 W/1 min) & + & - & + & NSP [16] \\
\hline $\begin{array}{l}\text { Blends of solvents miscible and } \\
\text { non-miscible in water }\end{array}$ & - & $\mathrm{OP} \rightarrow \mathrm{AP}$ & $\begin{array}{l}\text { Ultrasound ( } 50 \mathrm{~W} / 30 \mathrm{~s} \text {, in } \\
\text { an ice bath) }\end{array}$ & + & - & + & NSP [17] \\
\hline $\begin{array}{l}\text { Blends of solvents miscible and } \\
\text { non-miscible in water }\end{array}$ & - & $\begin{array}{c}\text { Two steps: } \\
\text { 1: } \mathrm{OP} \rightarrow \mathrm{AP}_{1} \\
\text { 2: } \mathrm{AP}_{1} \rightarrow \mathrm{AP}_{2}\end{array}$ & $\begin{array}{c}\text { Step 1: High stirring } \\
\text { (17,500 rpm } / 5 \text { min), Step 2: } \\
\text { Magnetic stirring }\left(40^{\circ} \mathrm{C} /\right. \\
40 \mathrm{~min}) .\end{array}$ & + & - & $\stackrel{+}{\left(40^{\circ} \mathrm{C}\right)}$ & $\begin{array}{l}\text { NSP, NC and } \\
\text { NE [18] }\end{array}$ \\
\hline \multicolumn{8}{|c|}{ Modification of the emulsification-diffusion method proposed in this study } \\
\hline $\begin{array}{l}\text { Blends of solvents miscible and } \\
\text { partially miscible in water }\end{array}$ & - & $\begin{array}{c}\mathrm{OP} \rightarrow \mathrm{AP} \\
\text { or } \mathrm{AP} \rightarrow \mathrm{OP} \\
(2 \mathrm{~mL} / \mathrm{min})\end{array}$ & $\begin{array}{c}\text { Low / medium shear } \\
\text { stirring (>1500-8000 rpm) }\end{array}$ & + & - & $\stackrel{+}{\left(30^{\circ} \mathrm{C}\right)}$ & NSP \\
\hline
\end{tabular}

+: Yes; -: Not; OP: Organic phase; AP: Aqueous phase; EVP: Evaporation; S: Use of Stabilizers; NSP: Nanospheres; SLN: Solid lipid nanoparticles; NC: Nanocapsules; MCP: Microcapsules and NE: Nanoemulsions; ACE: Acetone; F: Filtration; C: Centrifugation.

\section{Materials and Methods}

\subsection{Materials}

Poly (DL-lactide-co-glycolide) 85:15 (Mw 50,000-75,000, viscosity range: 0.55-0.75 dL/g in $\mathrm{CHCl3}$ ) and 50:50 (viscosity range: 0.55-0.75 dL/g in HFIP, Mw 30,000-60,000) ester terminated (PLGA); and dimethylaminoethyl methacrylate (Eudragit ${ }^{\circledR}$ E 100) were provided by Lactel, Durect Corporation (Birmingham, AL, USA) and Evonik Röhm GmbH (Darmstadt, Germany), respectively. They were used as the main polymers to constitute the nanoparticles. Polyvinyl alcohol 4-88, (PVA, EMPROVE $\left.{ }^{\circledR}\right)$, Poloxamer 407 (P-407, Lutrol ${ }^{\circledR}$ F127 NF M) were purchased from Merck KGaA, EMD Millipore Corporation (Waltham, MA, USA); BASF SE, Ludwigshafen, Germany); and BASF Corporation (Florham Park, NJ, USA), respectively, and they were used as stabilizers. Solvent mixtures of the following compounds HPLC grade were used as OP: Polyethylene glycol 400 (PEG 400 MW), obtained from Spectrum Chemical MFG CORP (New Brunswick, NJ, USA); Propylene glycol and benzyl alcohol (BnAl), acquired from Sigma-Aldrich Chemie GmbH, (Steinheim, Germany); Acetone (AC), methyl ethyl ketone (MEK), methylene chloride (MC), ethanol (Et), tetrahydrofuran (THF) and ethyl acetate (EtAc), purchased from Thermo Fisher Scientific (Branchburg, NJ, USA). Distilled and deionized water were used.

\subsection{Experimental Methods}

\subsubsection{Pre-Optimization of the Method to Produce Nanoparticles}

Biodegradable particles of PLGA (85:15 or 50:50) and pH-sensitive nanoparticles of Eudragit $^{\circledR}$ E100 were prepared by a modification of emulsion-diffusion process. These polymers and the stabilizers poloxamer 407 (P-407) and polyvinyl alcohol (PVA) were 
chosen for their safety $[20,21]$ and their wide use in nanoparticles. Firstly, and in order to skip the solvent saturation step, previous solubility and batches tests were carried out in different solvents and concentrations or using their blends (Table 2). In these first tests, the polymer PLGA (85:15) and (50:50) at $<2 \%(w / v)$ showed poor solubility with PEG 400 MW and Et as OP. Probe ultrasonication, able to improve their solubility in other study [26], was not used in order to develop a simple method.

Table 2. Nanoparticle optimization utilizing polymer, organic phase, and manufacturing parameters.

\begin{tabular}{|c|c|c|c|c|c|c|}
\hline Batch & $\begin{array}{l}\text { Stabilizer \% } \\
(w / v)\end{array}$ & $\begin{array}{c}\text { PLGA Type, \% } \\
(w / v)\end{array}$ & $\mathrm{AP}(\mathrm{mL})$ & OP \% $(v / v) \mathrm{mL}$ & Stirring & Ratio OP:AP \\
\hline \multirow{5}{*}{$a$} & \multirow{5}{*}{ PVA (2.0) } & \multirow{2}{*}{$(85: 15), 1$} & 0 & Et-PEG (90:10) 20 & * & \multirow{2}{*}{$(1: 0)$} \\
\hline & & & 0 & Et-PEG (80:20) 20 & * & \\
\hline & & (85:15), 1.4 & 0 & Et-PEG-THF (57.14:14.29:28.57) 28 & * & $(1.4: 0)$ \\
\hline & & (85:15), 1.8 & 0 & Et-PEG-THF (44.44:11.11:44.44) 36 & * & $(1.8: 0)$ \\
\hline & & $(85: 15), 1.4$ & 40 & Et-PEG-THF (36.36:9.509:54.54) 44 & Magnetic & $(1.05: 0.95)$ \\
\hline$b$ & PVA (2.0) & $(85: 15), 2.2$ & 40 & Et-MC (50:50) 20 & Magnetic & $(1: 2)$ \\
\hline$c$ & PVA (0.4545) & (50:50), 1 & 44 & EtAc-Et (71.43:28.57) 20 & Magnetic & $(0.77: 1.22)$ \\
\hline$d$ & PVA (2.0) & $(50: 50), 1$ & 40 & THF-PEG (80:20) 20 & Magnetic & $(1: 2)$ \\
\hline$e$ & PVA (2.0) & $(50: 50), 1$ & 40 & THF (100) 20 & Magnetic & $(1: 2)$ \\
\hline$f$ & PVA (2.0) & $(50: 50), 1$ & 40 & THF-EtAc-PEG (70:25:5) 20 & Magnetic & $(1: 2)$ \\
\hline$g$ & PVA (2.0) & (50:50), 1 & 40 & THF-EtAc (75:25) 20 & $\begin{array}{l}\text { Magnetic } 10 \mathrm{~min} \\
\text { + UT } 8000 \mathrm{rpm}, \\
10 \mathrm{~min}\end{array}$ & $(1: 2)$ \\
\hline$h$ & PVA (2.0) & $(50: 50), 0.5$ & 20 & THF (100) 20 & Magnetic & $(1: 1)$ \\
\hline$i$ & PVA (2.0) & $(50: 50), 0.5$ & 40 & THF (100) 20 & Magnetic & $(1: 2)$ \\
\hline$j$ & PVA (2.0) & $(50: 50), 1$ & 40 & THF-EtAc (50:50) 20 & UT, 8000 rpm * & $(1: 2)$ \\
\hline
\end{tabular}

PLGA: Poly (DL-lactide-co-glycolide) 85:15 and 50:50; PEG: polyethylene glicol 400; Et: MC: methylene chloride; THF: tetrahydrofuran; EtAc: ethyl acetate; UT: Ultra-Turrax ${ }^{\circledR}$ homogenizer. ${ }^{*}$ Incomplete solubilization, emulsification step was not followed, $(n=3)$.

On the other hand, THF with Et and high volumes of MC as OPs, produced coarse aggregates (Figure S1 of the Supplementary Material). Thus, MC was not further used because of its considerable toxicity [27]. Probes with solvent blends of partially water miscible solvents and water miscible solvents, as OPs, were able to dissolve PLGA (50:50 or 85:15). Here, attempts to produce nanoparticles varying the stirring type were performed. Magnetic stirring (10 min) used to emulsify the OPs and APs, skipping the water addition after the emulsification process and followed by the organic solvent removal by vacuum steam distillation at $30^{\circ} \mathrm{C}$, produced heterogeneous microparticles with an unwanted film. A little improvement was obtained using PLGA 50:50 instead PLGA 85:15 (due to its higher polymer hydrophilicity and solubility [28]) or using THF (100\%) or decreasing the polymer concentration (Table 2).

With the intention to obtain unimodal particle size distributions in the nanometer scale, magnetic stirring (10 min) followed by high shear stirring (IKA Ultra-Turrax ${ }^{\circledR} \mathrm{T} 25$, IKA Works, Inc., Wilmington, NC, USA) at $8000 \mathrm{rpm} / 10 \mathrm{~min}$ were probed. However, after the solvent removal step, two particle size distributions around $200 \mathrm{~nm}$ and $1200 \mathrm{~nm}$ were found (batch $g$, Table 2). Finally, an unimodal particle size distribution around $\sim 190 \mathrm{~nm}$ was achieved only adding dropwise $(2 \mathrm{~mL} / \mathrm{min}$ ) the THF-EtAc (50:50) blend as OP into the AP simultaneously stirred with mechanical high shear stirring at $8000 \mathrm{rpm}$ for $10 \mathrm{~min}$ (batch $j$, Table 2). All other operating conditions were kept constant (detailed results available in Figure S1 of the Supplementary Material). 


\subsubsection{Nanoparticle Preparation and Experimental Design}

Once the method to prepare nanoparticles was pre-optimized, 12 experimental designs (Table 3) were performed in order to determine the method space design and the influence of the formulation and operating parameters. All formulations from these experimental designs were prepared by dissolving the polymer (PLGA (50:50) or Eudragit ${ }^{\circledR}$ E100 in the OPs, consisting of solvent blends of partially water-miscible solvents and water-miscible solvents. THF-EtAc, ACE-MEK, ACE- EtAc and Et-EtAc were used as solvent blends. These OP solutions were added dropwise $(2 \mathrm{~mL} / \mathrm{min})$ into an aqueous solution containing PVA or P-407 constantly stirred, used as stabilizers. The OP and AP volumes were kept constant in all batches with a ratio of 1:2, respectively. The emulsification was performed using either a mechanical stirrer Caframo Model BDC3030 (Georgian Bluffs, ON, Canada) with a 4-bladed propeller stirrer or under mechanical high shear stirring (IKA Ultra-Turrax ${ }^{\circledR} \mathrm{T} 25$, IKA Works, Inc., Wilmington, NC, USA) at $8000 \mathrm{rpm}$ for $10 \mathrm{~min}$. No water addition was done after the emulsification step. Finally, the organic solvent was removed by vacuum steam distillation at $30^{\circ} \mathrm{C}$.

Thus, the effect of using solvent blends miscible and partially miscible in water, with different polarity/acidity, varying their ratios, and using high shear stirring in the emulsification step, on size, PdI and zeta potential of PLGA nanoparticles was studied (Experimental design 1, Table 3).

Regarding Eudragit ${ }^{\circledR}$ E100, it was used to prepare nanoparticles in the experimental designs $2-6$ and 8 . The effect of increasing the polymer concentration varying the watermiscible solvent ratio in the solvent blend (Experimental design 2, Table 3), and the effect of using a different water-miscible solvent varying its ratio in the solvent blend, on the size, PdI and zeta potential of Eudragit ${ }^{\circledR}$ E100 nanoparticles were investigated (Experimental design 3, Table 3). A three factor (two stabilizers, three stabilizer concentrations and four ratios of the solvent blend as $\mathrm{OP}$ ) experimental design was also carried out to evaluate the behavior on the particle sizes, PdIs, electrical charges and the $\mathrm{pH}$ (Experimental design 4, Table 3). Batches with increasing stirring rates in a feasible range to emulsify the AP and $\mathrm{OP}$ were manufactured in order to determine the range to produce particles in the nanometer scale by using a mechanical stirrer Caframo Model BDC3030 (Georgian Bluffs, ON, Canada) with a 4-bladed propeller stirrer (Experimental design 5, Table 3). The effect of the use of a higher polymer concentration, versus the use of a more polar solvent blend, varying its ratios into the OP, (Experimental design 6, Table 3) was studied. The effect of varying the concentration of polymer and stabilizer (Experimental design 8, Table 3) was also evaluated.

PLGA (50:50) was also used in the experimental designs 7 and 9-12, (Table 3). The influence in the order of the aqueous and organic phase's addition in the emulsification step on the particle size, PdI and Zeta potential was studied (Experimental design 7). The effect of the three lowest stabilizer concentrations (Experimental design 9) and the highest stabilizer concentration versus two solvent blend ratios (Experimental design 10) were also studied. Finally, the effect of using two solvents blends with different polarity varying their ratios (Experimental design 11), as well as the effect of using two different stabilizers (Experimental design 12) on the particle size distribution, electrical charges and $\mathrm{pH}$ were analyzed. Surface-response plots from all experimental designs were built to analyze the design space of the method. All the operating and formulation parameters used in the experimental designs are shown in Table 3. 
Table 3. Experimental designs performed using the rapid emulsification-diffusion method.

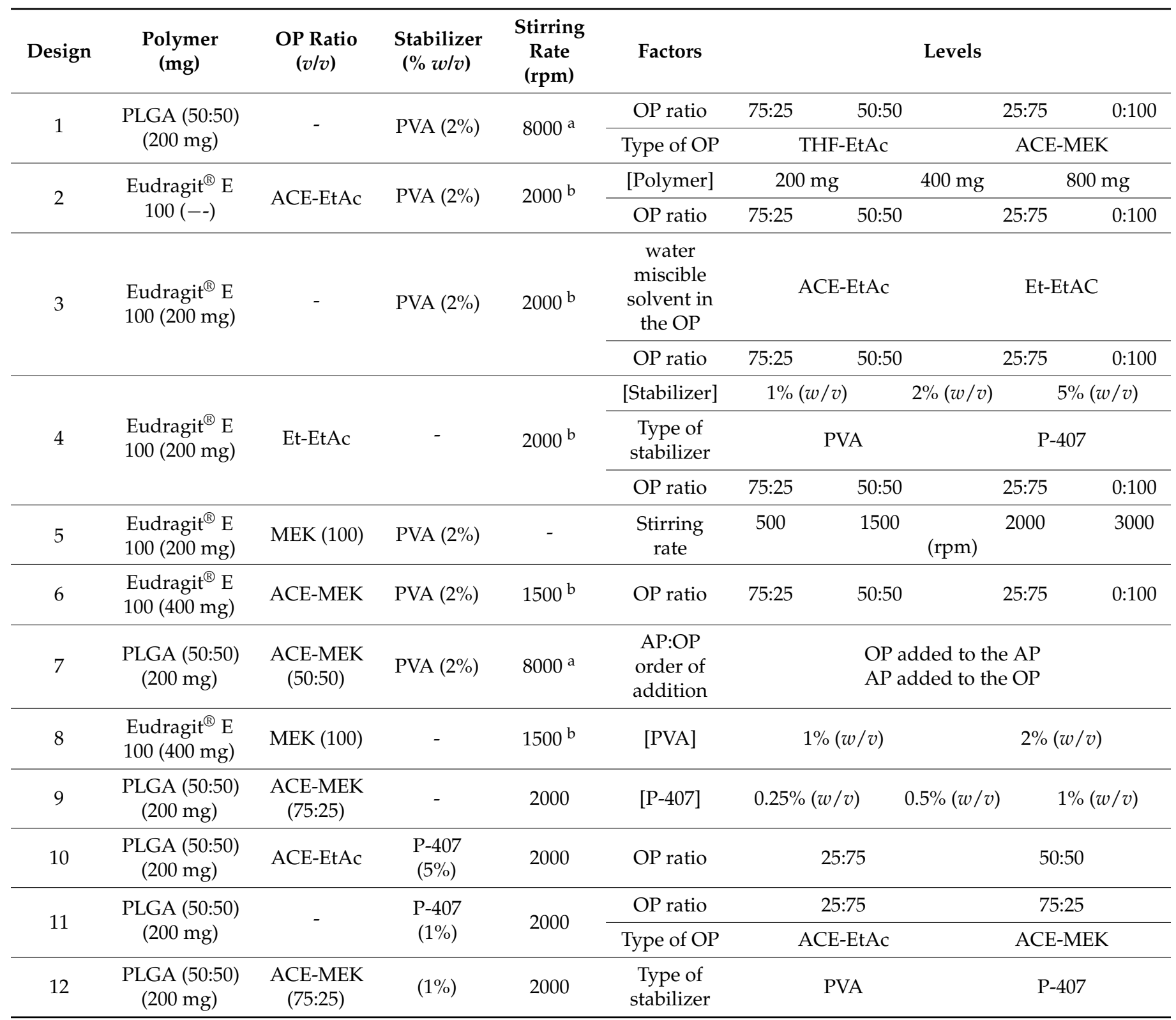

PLGA: Poly (DL-lactide-co-glycolide) 50:50; OP ratio: ratios of the water miscible solvent and a partially watermiscible solvent; PVA: polyvinyl alcohol; ACE: acetone; MEK: methyl ethyl ketone; P-407: Poloxamer 407. All the systems were prepared with OP: $20 \mathrm{~mL}$; AP: $40 \mathrm{~mL} ;(n=3) .{ }^{\text {a }}$ Systems emulsified with Ultra-Turrax ${ }^{\circledR}$. ${ }^{\mathrm{b}}$ Systems emulsified with a mechanical stirrer and a 4-bladed propeller stirrer.

\subsubsection{Particle Size, Charge and $\mathrm{pH}$ Determination}

NPs average size, polydispersity index and zeta potential analysis of the NPs were determined using a Zetasizer (Nano series Nano-ZS, Malvern Panalytical, Enigma Business Park, Malvern, UK). Measurements for all batches were conducted at $25^{\circ} \mathrm{C}$, at the water viscosity and using dynamic light scattering with non-invasive backscatter optics (NIBS, $n=3$ ). Zeta potential of all batches was determined at $25{ }^{\circ} \mathrm{C}$ using the viscosity and dielectric constant of water, using deionized water as a dispersion medium.

Dispersions were diluted with distilled water to ensure that the count rate of particles was within the sensitivity range of the instrument for all measurements $(n=3)$. NP final suspensions prepared with Eudragit ${ }^{\circledR}$ E100 and solvent blends of Et-EtAc (0:100) at ratios from 25 to $100 \%$ were used to determine the $\mathrm{pH}$, as well as the suspensions obtained in the experimental designs 11 and 12 (Table 3) using PLGA (50:50). Measurements were 
directly collected from the NP suspensions at constant and moderate stirring after suitable pH-meter calibration $(n=3)$.

\subsubsection{Determination of Solubility Parameters of the Nanoparticles Components}

Solubility parameters of the solvent blends were calculated and used for comparison to study the correlation with the nanoparticle formation in this study. The solubility parameter was introduced by Hildebrand and Scott to determine an estimation of the drug/excipient miscibility [29]. Hildebrand defined the solubility parameter, $\delta_{T}$, as square root of the cohesive energy density, $E_{P}$, of a substance. This is the energy required to separate or attract the atoms or molecules from each other.

$$
\Delta \delta_{T}=\left(\Delta H_{v}-R T / V_{m}\right)^{0.5}
$$

where $\Delta H_{v}$ is the heat of vaporization, $R$ is the gas constant, $T$ is the temperature and the molar volume is $V_{m}$. This equation was developed for simple liquid mixtures and their use is limited for non-polar solvents. Derivatives approximations of Hildebrand's equation have been described to better establish the interactions between substances. One of these is the Hansen approach [30]. $H_{a S P}$ is derived from three different solvent energies: $E_{D}$ measured as the intermolecular dispersion energy, $E_{P}$ as the dipolar intermolecular energy, and $E_{H}$ as the hydrogen bonding energy. The sum of the square energies divided by the molar volume, $V_{m}$, is the square of the total solubility parameter [30],

$$
\delta_{T}^{2}=\delta_{H a S P}^{2}=\delta_{D}^{2}+\delta_{P}^{2}+\delta_{H}^{2}
$$

$\delta^{2} \mathrm{HaSP}$ of the pure solvents were obtained from the literature [31] and the solubility parameters of the solvent blends were calculated as the sum of the solubility parameter values of the pure solvents by their volume fraction as previously reported [32]. The calculated solubility parameters of the solvent blends were plotted with the particle size values from batches prepared with the respective solvent blends used as OPs at the same operating condition. A linear regression analysis was performed, and the correlation coefficient was determined.

\subsubsection{Statistical Analysis}

The results were statistically evaluated by analysis of variance (ANOVA) one-way to compare two or multiple groups. Post-hoc comparisons of individual group means of one or more factors were performed applying the Bonferroni test. Differences were considered significant if $p$ value $<0.05$. When variances of multifactorial groups were different, analysis per individual factor was performed. Models were constructed to produce three-dimensional response surface plots to analyze the influence of each response using data from the experimental designs with different factors and levels (Table 3). Software STATGRAPHICS Centurion XVI was used for this purpose.

\section{Results and Discussion}

A rapid emulsion-diffusion method to prepare polymeric nanoparticles ( $\mathrm{pH}$-sensitive polymeric or biodegradable) for general applications was achieved. This reduced method was performed by using aqueous and organic phases with no previous mutual saturation. The OPs consisted of partially water-miscible solvents and water-miscible solvents varying their ratios in order to produce nanoparticles of $50 \leq 1000 \mathrm{~nm}$, using either low or high shear stirring (1500-8000 rpm) from straightforward equipment. No water addition after the emulsification step was carried out, reducing the time of NPs processing (Tables 1-3; detailed results can be found in Table S1 of the supplementary material). An important linear correlation was found to predict the particle size from the solubility parameters of the OPs (Table 4). 
Table 4. Hansen solubility parameters of pure solvents and solvent blends used to prepare nanoparticles.

\begin{tabular}{ccccc}
\hline \multirow{2}{*}{ Pure Solvents and Solvent Blends } & \multicolumn{4}{c}{ Hansen Solubility Parameter (MPa $^{\mathbf{1 / 2}}$ ) } \\
\cline { 2 - 5 } & $\boldsymbol{\delta}_{\boldsymbol{D}}$ & $\boldsymbol{\delta}_{\boldsymbol{P}}$ & $\boldsymbol{\delta}_{\boldsymbol{H}}$ & $\boldsymbol{\delta}_{\boldsymbol{H} \boldsymbol{a S P}}$ \\
\hline ACE 100\% & 15.5 & 10.4 & 7 & 19.9 \\
EtAc 100\% & 15.2 & 5.3 & 9.2 & 18.5 \\
MEK 100\% & 15.9 & 9 & 5.1 & 19.0 \\
THF 100\% & 16.8 & 5.7 & 8 & 19.5 \\
Et 100\% & 15.8 & 8.8 & 19.5 & 26.6 \\
ACE-MEK (0:100) & 15.9 & 9.0 & 5.1 & 19.0 \\
ACE-MEK (25:75) & 15.8 & 9.4 & 5.6 & 19.2 \\
ACE-MEK (50:50) & 15.7 & 9.7 & 6.1 & 19.4 \\
ACE-MEK (75:25) & 15.6 & 10.1 & 6.5 & 19.7 \\
THF-EtAc (0:100) & 15.2 & 5.3 & 9.2 & 18.6 \\
THF-EtAc (25:75) & 15.6 & 5.4 & 8.9 & 18.8 \\
THF-EtAc (50:50) & 16.0 & 5.5 & 8.6 & 19.0 \\
THF-EtAc (75:25) & 16.4 & 5.6 & 8.3 & 19.2 \\
ACE-EtAc (0:100) & 15.2 & 5.3 & 9.2 & 18.6 \\
ACE-EtAc (25:75) & 15.3 & 6.6 & 8.7 & 18.7 \\
ACE-EtAc (50:50) & 15.4 & 7.9 & 8.1 & 19.0 \\
ACE-EtAc (75:25) & 15.4 & 9.1 & 7.6 & 19.4 \\
Et-EtAc (0:100) & 15.2 & 5.3 & 9.2 & 18.6 \\
Et-EtAc (25:75) & 15.4 & 6.2 & 11.8 & 20.3 \\
Et-EtAc (50:50) & 15.5 & 7.1 & 14.4 & 22.3 \\
Et-EtAc (75:25) & 15.7 & 7.9 & 16.9 & 24.4
\end{tabular}

Solubility parameters of the pure solvents were obtained from the literature [31] and the solubility parameters of the solvent blends were calculated as described in the method section.

\subsection{Pre-Optimization of the Rapid Emulsion-Diffusion Method}

A single mode distribution of the batch (particles below $200 \mathrm{~nm}$ and PdI of 0.054) was only achieved by adding dropwise the $\mathrm{OP}$ into the $\mathrm{AP}$ or vice versa using high shear stirring at $8000 \mathrm{rpm}$, as shown in Table 2. This contrasts with the results from a previous study using the standard method in which the dropwise addition or total addition of the OP into the AP did not influence the particle size distribution [2]. Systems magnetically stirred for $10 \mathrm{~min}$ adding dropwise the OP into the AP and subsequently stirred using a homogenizer of high shear at $8000 \mathrm{rpm}$ for $10 \mathrm{~min}$, were not able to produce unimodal particle size distributions. Two populations in the micro and nanoscale were obtained.

\subsection{Influence of the Process and Formulation Parameters}

Interesting results are found from the experimental designs determining the space design in which NPs can be formed using this rapid emulsion-diffusion method. Biodegradable or $\mathrm{pH}$-sensitive nanoparticles $(<1000 \mathrm{~nm})$ were robustly produced by using solvent blends consisting of partially water-miscible solvent and water-miscible solvents, as OPs, to be emulsified with an AP containing a stabilizer. Low shear stirring (1500-3000 rpm) with a mechanical stirrer or high shear stirring $(8000 \mathrm{rpm})$ with an Ultra Turrax ${ }^{\circledR}$ stirrer were good enough to produce nanoparticles. The dropwise addition of the OP into the AP or the inverse order in the emulsification step was able to produce nanoparticles, though smaller particle sizes were obtained in the first case. Important tendencies and a linear correlation to decrease the particle size by increasing the solubility parameter were found. This suggests that the formation of the nanoparticles is given in the emulsification step and a prediction of the particle size can be done by knowing the OP solubility parameter.

Among the trends observed, the decrease in the partially water-miscible solvent ratio and simultaneously increasing the water-miscible solvent, increasing the OP polarity, or using higher concentrations of PVA or lower concentrations of P-407 with higher ratios of the water-miscible solvent, produced smaller sizes and PdIs using either Eudragit ${ }^{\circledR} \mathrm{E}$ 100 or PLGA (50:50). In contrast, smaller sizes and PdIs were obtained using 100\% $(v / v)$ of a less polar partially water-miscible solvent (i.e., EtAc compared with MEK). Using 
either Eudragit ${ }^{\circledR}$ E 100 or PLGA 50:50, a wide range of particle sizes could be obtained $(\sim 50 \geq 600 \mathrm{~nm})$ when P-407 was used. At its lowest concentration however $(1 \%, w / v$ P-407), smaller particle sizes were obtained compared with polyvinyl alcohol across the tested concentration range $(1-5 \%, w / v$; Figures $1-7)$. In general, similar particle sizes were found using the closest solubility parameters of the solvent blends/polymers/stabilizers. Using higher ratios of a water-miscible solvent into the OP or increasing the stabilizer concentration, lower absolute values of NPs zeta potential were obtained with either Eudragit ${ }^{\circledR}$ E 100 or PLGA (Table 3). A higher ionization of the polymeric molecules was confirmed measuring the $\mathrm{pH}$ from these nanoparticle aqueous dispersions. All the explanations to these effects on the responses studied are provided in detail in the following subsections.
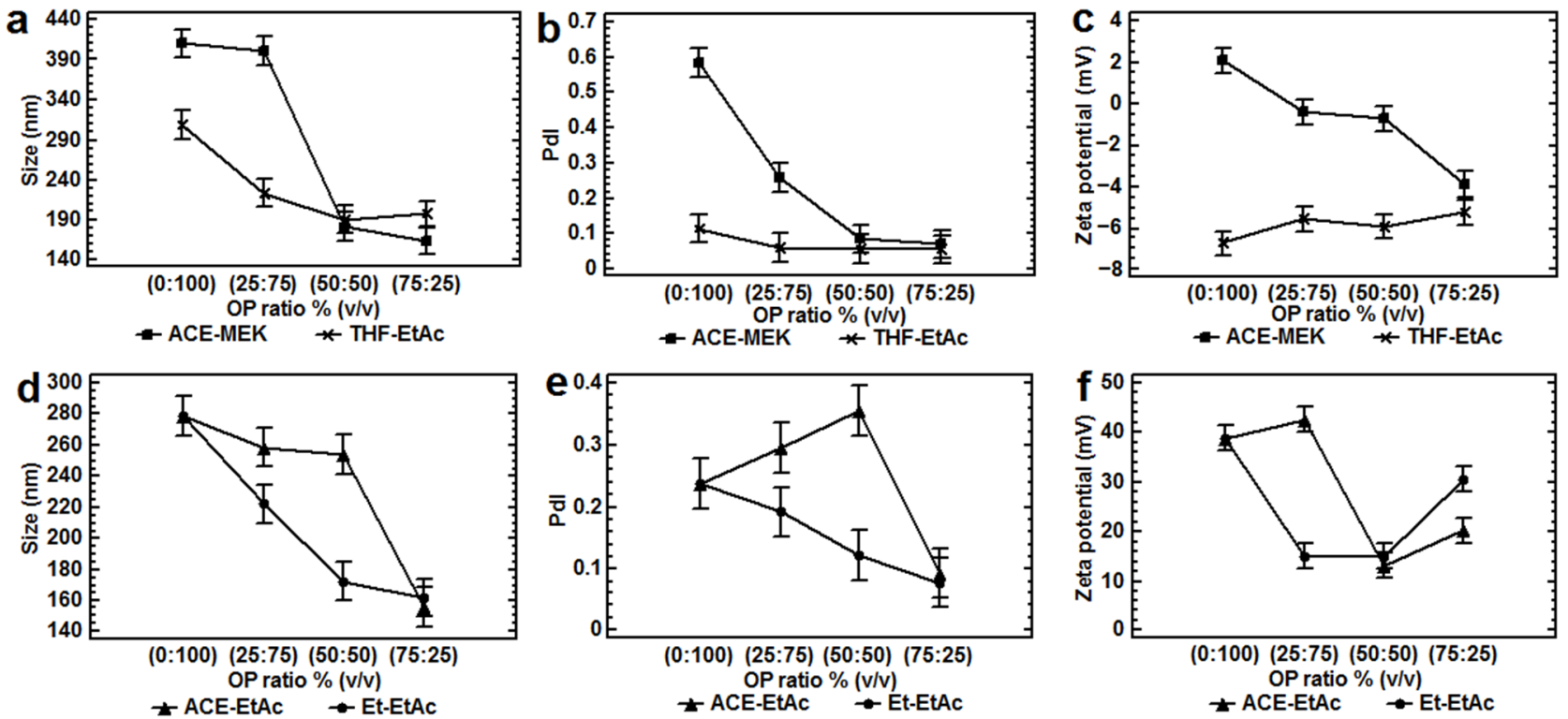

Figure 1. Influence of different organic phases at different ratios on the particle size, polydispersity index and zeta potential by using two polymers: (a-c) PLGA (50:50), $8000 \mathrm{rpm}$; (d-f) Eudragit ${ }^{\circledR}$ E100, $2000 \mathrm{rpm}$. All batches were prepared with $200 \mathrm{mg}$ of polymer, a ratio of OP:AP (1:2), PVA 2\%, $n=3$. All the means bars correspond to the Bonferroni interval at the $95.0 \%$ confidence level.
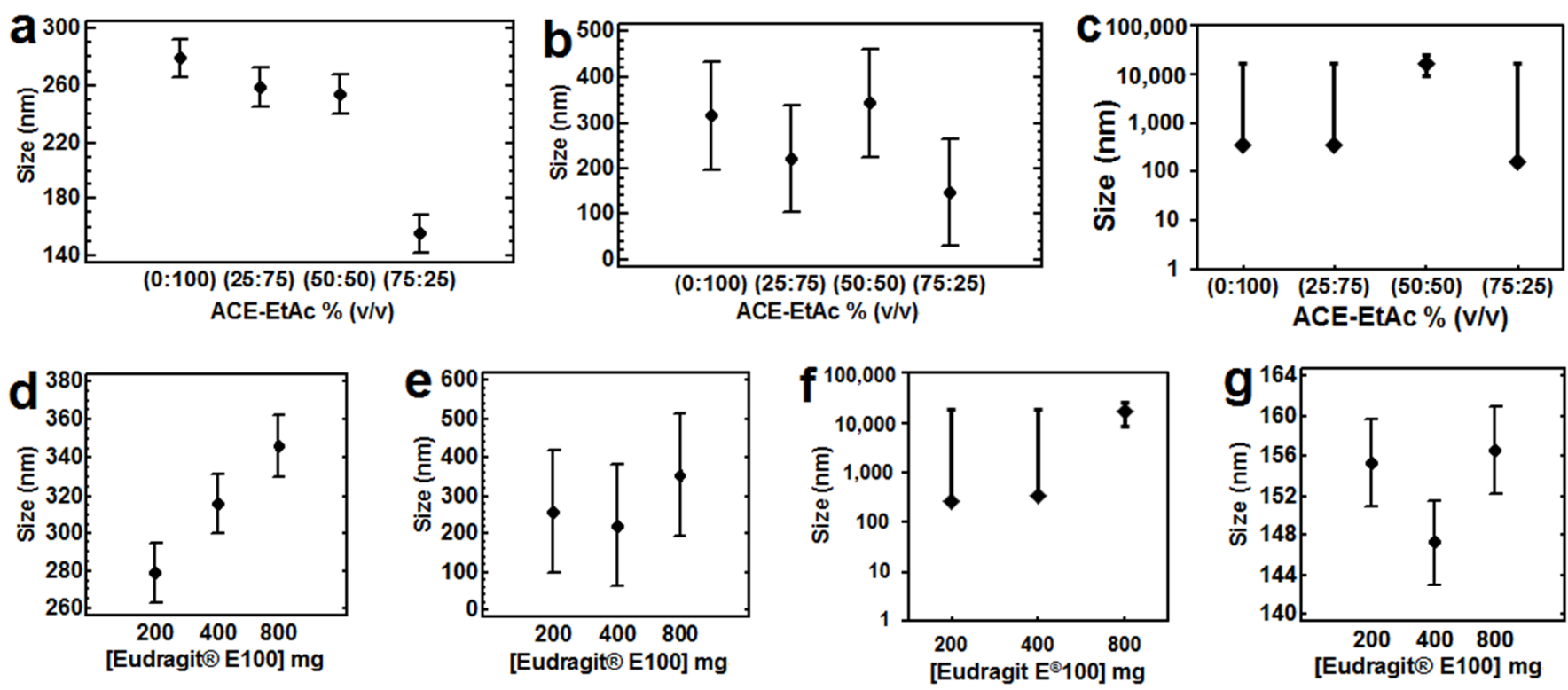

Figure 2. Cont. 

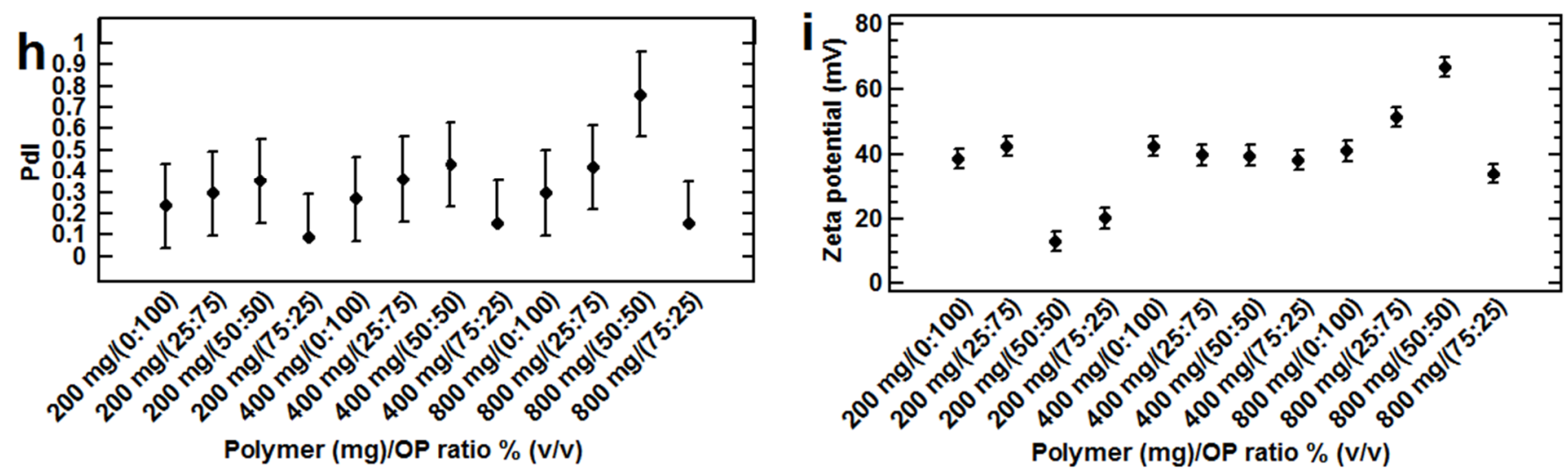

Figure 2. Influence of the polymer concentration (a) $200 \mathrm{mg}$; (b) $400 \mathrm{mg}$ and (c) $800 \mathrm{mg}$ and the OP ratio of ACE-EtAc (d) 0:100; (e) 25:75; (f) 50:50 and (g) 75:25\% (v/v) on the particle size (h) PdI and (i) zeta potential. All batches were prepared with Eudragit ${ }^{\circledR}$ E 100, ACE-EtAC as OP, a ratio OP:AP (1:2), $2000 \mathrm{rpm}$, PVA 2\%, $n=3$ (Experimental design 2). All the means bars correspond to the Bonferroni interval at the $95.0 \%$ confidence level.
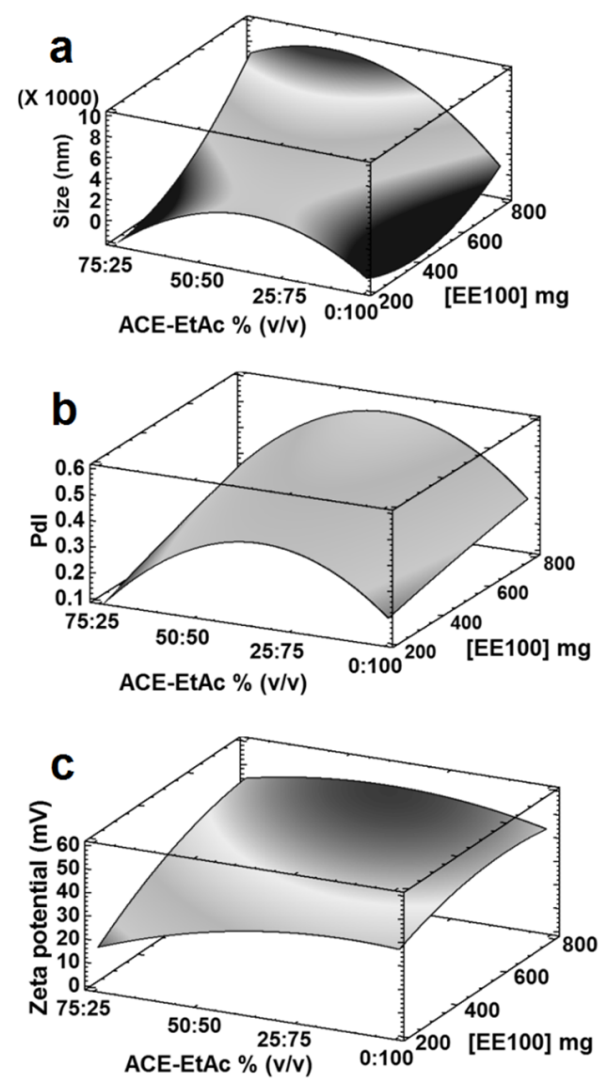

Figure 3. Three-dimensional model showing the response-surface estimated; (a) particle size, (b) PdI and (c) zeta potential by using ACE-EtAc, as OP, varying its ratios, and Eudragit ${ }^{\circledR}$ E 100 (EE100) at three concentrations (Table 3, design 2). All batches were prepared with a ratio OP:AP (1:2), $2000 \mathrm{rpm}$, PVA $2 \%, n=3$. 

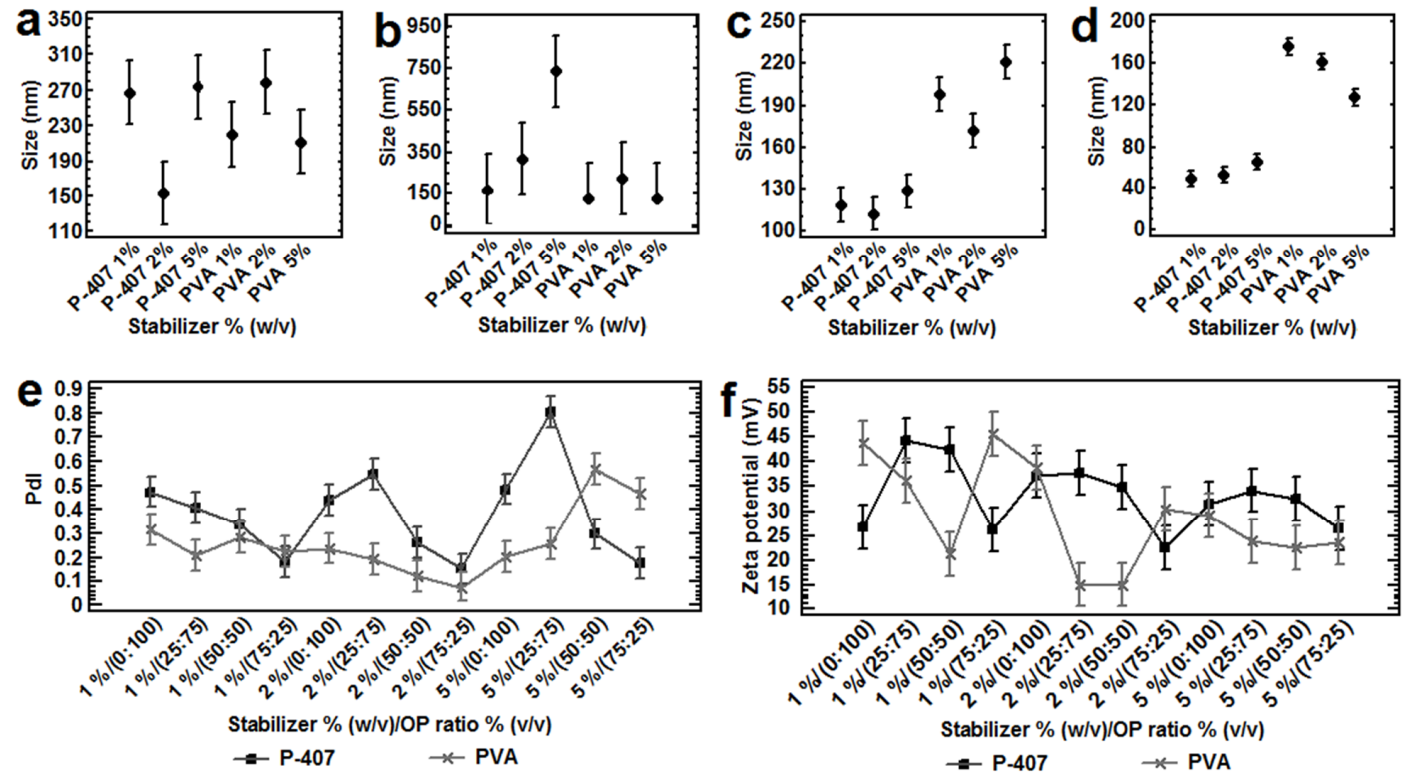

Figure 4. Influence of the OP ratio of Et-EtAC at (a) 0:100; (b) 25:75; (c) 50:50 and (d) 75:25, type of stabilizer and its concentration $\%(w / v)$ on the (a-d) particle size, (e) PdI and (f) zeta potential. All batches were prepared with $200 \mathrm{mg}$ of Eudragit ${ }^{\circledR}$ E 100, a ratio OP:AP (1:2), $2000 \mathrm{rpm}, n=3$ (experimental design 4). All the means bars correspond to the Bonferroni interval at the $95.0 \%$ confidence level.
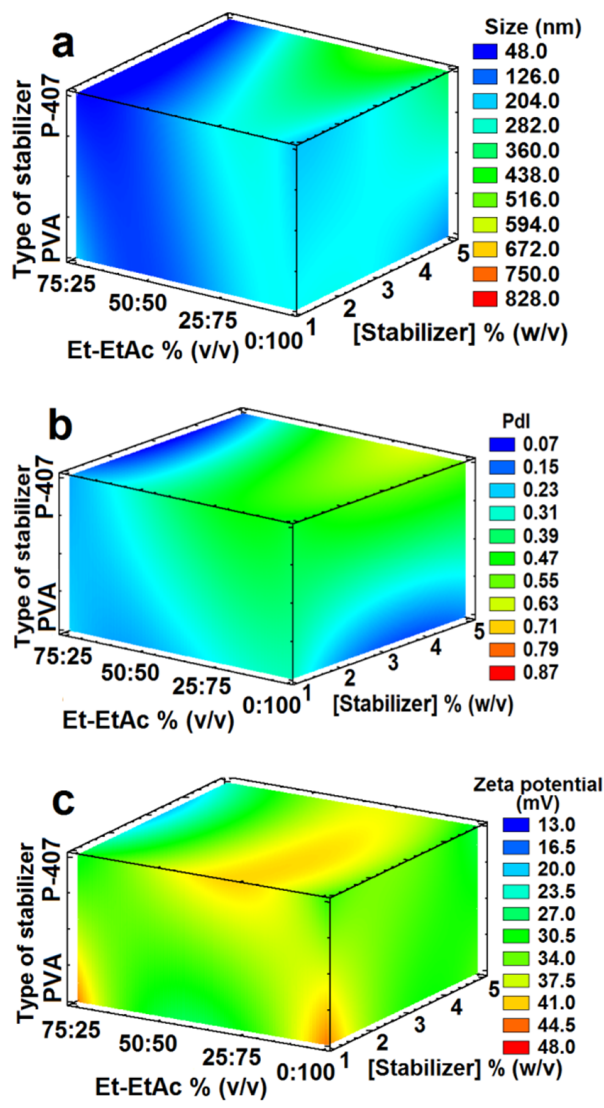

Figure 5. Three-dimensional model showing the response-surface estimated; (a) particle size, (b) PdI and (c) zeta potential by using Et-EtAc varying its ratios and two stabilizers (P-407 or PVA) also varying their concentrations (Table 3, Experimental design 4). All batches were prepared with $200 \mathrm{mg}$ of Eudragit ${ }^{\circledR}$ E 100, a ratio OP:AP (1:2), $2000 \mathrm{rpm}, n=3, p<0.05$. 

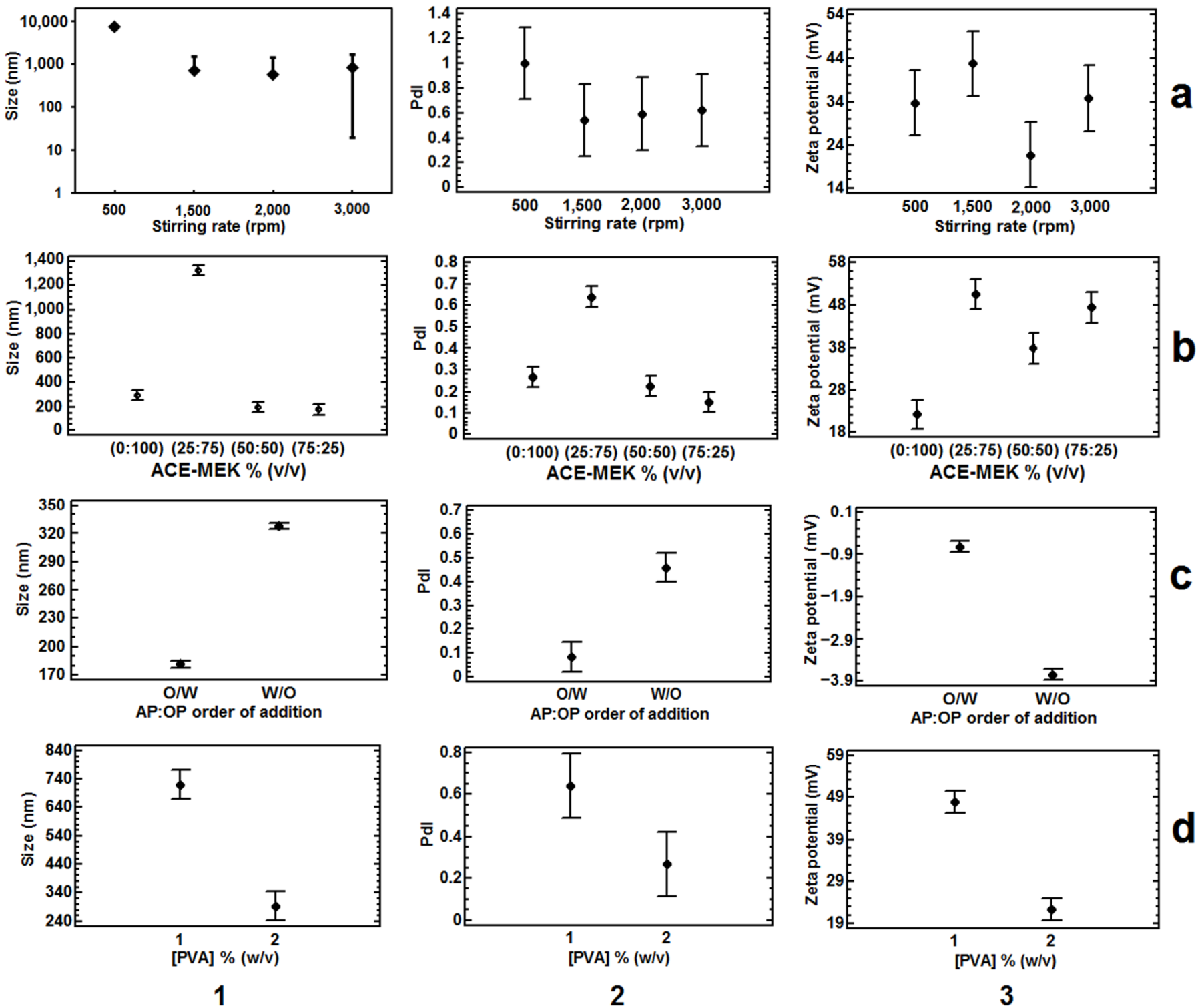

Figure 6. Influence of (a) the stirring rate (Experimental design 5); (b) the solvent blend ratios using $400 \mathrm{mg}$ of Eudragit ${ }^{\circledR}$ E 100 (Experimental design 6); (c) the AP:OP order of addition (Experimental design 7); and (d) the stabilizer concentration using $400 \mathrm{mg}$ of Eudragit ${ }^{\circledR}$ E 100 (Experimental design 8) on the (1) particle size, (2) PdI and (3) Zeta potential. All batches were prepared with a ratio OP:AP (1:2). All the bars of all means correspond to the Bonferroni interval at the $95.0 \%$ confidence level, $n=3$.

\subsubsection{Effect of the Solvent Blend (OP) Composition/Ratio on Particle Size and PdI}

In general terms, smaller sizes and PdIs were found increasing the solubility of either polymer (PLGA or Eudragit ${ }^{\circledR}$ E 100) in the organic phase. The solubility as a factor to modulate the particle size was analyzed using the relative polarity, tension surface and the solubility parameter, from the existing literature, of the components used to produce the nanoparticles in this study. The relative polarity used [33] is the empirical normalized solvent parameter $\mathrm{E}^{\mathrm{N}} \mathrm{T}$, derived from the solvatochromism or transition energy at $25{ }^{\circ} \mathrm{C}$ of the long-wavelength visible absorption of a standard of a pyridinium $\mathrm{N}$-phenolate betaine dye, which decreases as the polarity decreases [34]. Regarding the tension surface, a correlation has also been reported between the increase in the surface tension of organic solvent to produce a smaller contact angle and induce an easier imbibition of water due to the decrease in the interfacial tension between water and organic solvent [35]. On the other 
hand, according to Hildebrand's solubility parameter approach, a higher mutual solubility will be given if the solubility parameter values of the solvents/polymers are closer [29].
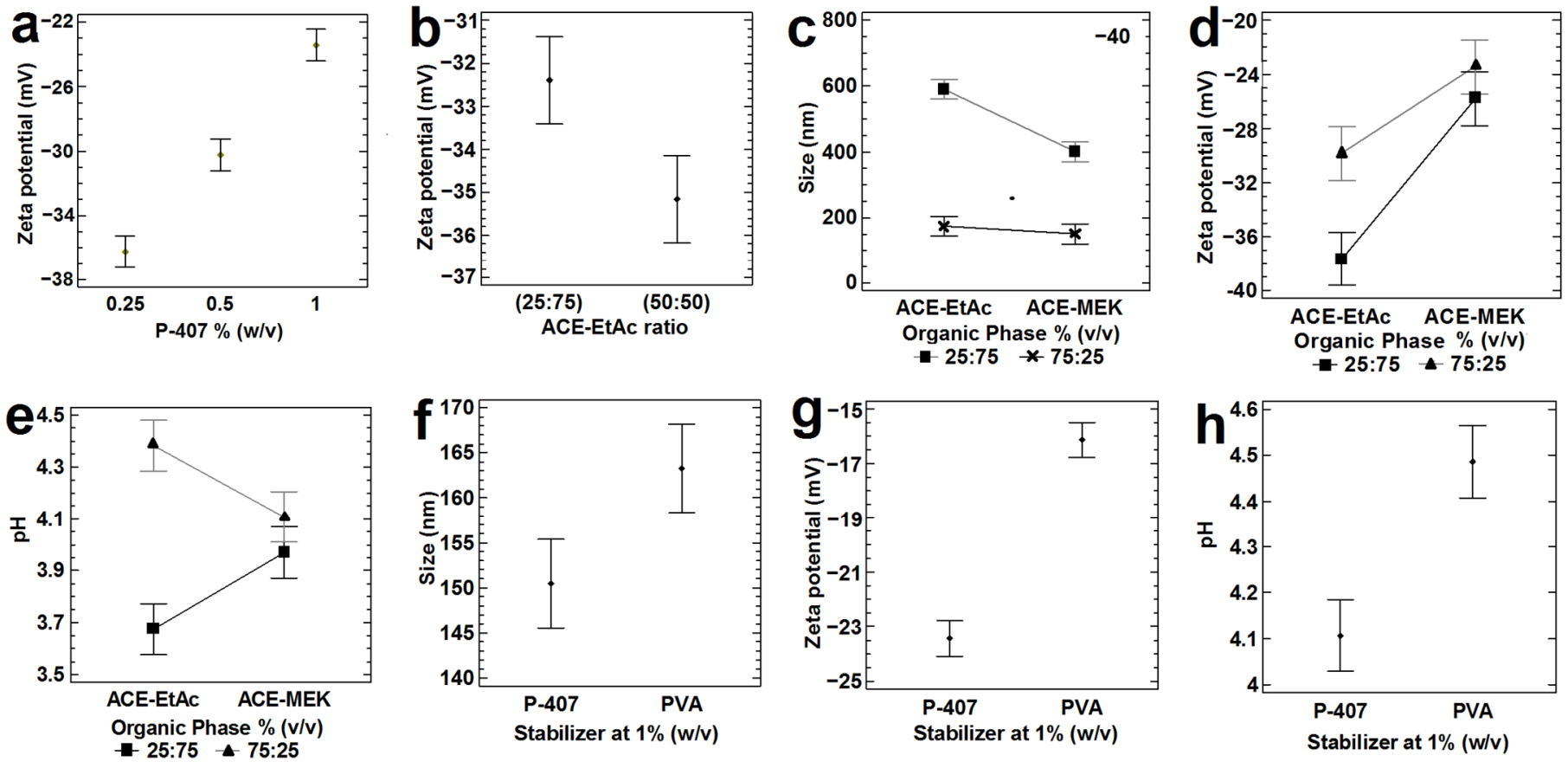

Figure 7. Influence of (a) P-407 at three low concentrations using ACE-MEK (75:25), Experimental design 9; and (b) ACE-EtAc at two ratios using P-407 5\% (w/v; Experimental design 10), on the zeta potential. Effect of two solvent blends, as OP, at two ratios on (c) the particle size, (d) zeta potential and (e) pH by using P-407 1\%, as stabilizer (Experimental design 11). Influence of P-407 and PVA at $1 \%$, on the (f) particle size, (g) zeta potential and $(\mathbf{h}) \mathrm{pH}$, by using the solvent blend ACE-MEK (75:25), Experimental design 12. All batches were prepared with $200 \mathrm{mg}$ of PLGA (50:50), $2000 \mathrm{rpm}$, and a ratio of OP:AP (1:2), $n=3$. All the means bars correspond to the Bonferroni interval at the $95.0 \%$ confidence level.

Analyzing the systems with PLGA (50:50) and PVA at 2\% (w/v), in which the partially water-miscible solvent was used at $100 \%(w / v)$, interesting results were obtained. Significantly $(p<0.05)$ smaller nanoparticles $(\sim 300 \mathrm{~nm})$ and PdIs $(\sim 0.1)$ were found using EtAc (relative polarity $=0.228[33,34]$ and surface tension $=23.2 \mathrm{mN} / \mathrm{m}$ at $25^{\circ} \mathrm{C}[36]$ ), a less polar partially water-miscible solvent, compared with MEK (relative polarity $=0.327[33,34]$ and surface tension $=24.0 \mathrm{mN} / \mathrm{m}$ at $25^{\circ} \mathrm{C}$ [36]) as OP. This effect was also evident at higher ratios $(75 \%, v / v)$ of this less polar partially water-miscible solvent (EtAc) mixed with $25 \%$ $(w / v)$ of THF into the OP (Table 3, Experimental design 1; Figure 1a,b). Similar results were found in other studies using PLGA (50:50) and ethyl acetate (relative polarity: 0.228 [33,34]) compared with methylene chloride (relative polarity: 0.309 [33,34]) by emulsificationevaporation [16] and emulsion-diffusion-evaporation methods [11]. The same behavior was found using Eudragit ${ }^{\circledR}$ E100, PVA at $2 \%(w / v)$ and the same partially water-miscible solvents at 100\% ( $w / v$; Table 3, Experimental design 2 and 5; Figures $1 \mathrm{~d}$ and $6 \mathrm{a})$. The higher particle sizes obtained with MEK as OP could be due to its higher surface tension compared with that of the EtAc.

In contrast, using P-407 at 1\% (w/v), PLGA 50:50 and a more polar solvent blend as OP, consisting of 25:75 of ACE-MEK compared with ACE-EtAc (ACE relative polarity $=0.355$; surface tension $=23.0 \mathrm{mN} / \mathrm{m}$ at $25^{\circ} \mathrm{C}$ [36]), significantly smaller sizes (around $400 \mathrm{~nm}$, $p<0.05$ ) and PdIs (0.5) were found. Moreover, in PLGA systems stabilized with either PVA or P-407, a decrease in the particle size below $200 \mathrm{~nm}$ and PdI around 0.1 was also found decreasing the ratio of the partially water-miscible solvents into the OPs and simul- 
taneously increasing the ratios of the water-miscible solvents ACE or THF (THF relative polarity $=0.207[33,34]$, and surface tension: $\mathrm{THF}=26.7 \mathrm{mN} / \mathrm{m}$ at $25^{\circ} \mathrm{C} \mathrm{[36];} \mathrm{ACE} \mathrm{relative}$ polarity $0.355[33,34]$; and surface tension $=23.0 \mathrm{mN} / \mathrm{m}$ at $25^{\circ} \mathrm{C}$ [36]) in the OPs (Table 3 , Experimental design 1, Figure 1a,b,d,e; Experimental design 11, Figure 7c). More results can be found in the Figure S2 of the Supplementary Material.

When Eudragit ${ }^{\circledR}$ E100 was used, similar trends were found. By using a more polar water-miscible solvent (Ethanol: relative polarity $=0.654[33,34]$ ) in the solvent blend EtEtAc, compared with ACE-EtAc (ACE relative polarity $0.355[33,34]$ ), statistically significant $(p<0.05)$ smaller sizes (around $200 \mathrm{~nm}$ ) and PdIs (0.2) were found (Table 3, Experimental design 3; Figure 1d,e). The same tendency to decrease the particle size was also found, by decreasing the ratio of the partially water-miscible solvents and increasing simultaneously the water-miscible solvents in the OPs and using either PVA or P-407 (Table 3, Experimental designs 2, 3 and 4; Figures 1d,e, 2a,c,h, 3a,b, 4a-e and 5a,b). This effect was more evident using $200 \mathrm{mg}$ of Eudragit ${ }^{\circledR}$ E100 instead of $400 \mathrm{mg}$ (Table 3, Experimental design 2 and 6 ; Figures $2 a-c, 3 a$ and $6 b$ ). This agrees with the results found in another study using the blend chloroform:ethanol as OP and the emulsification-diffusion process [18]. Nevertheless, NPs could not be produced in other study with ACE (saturated with glucose)-EtAc at ratios of 70:30 and 80:20 by emulsion-diffusion-evaporation method [11].

These trends were evaluated plotting the solubility parameter calculated for each ratio of each solvent blend, used as OP, versus the particle size values (Tables 4 and 5). The results agree with the above explanation, in which the decrease in the partially watermiscible solvents into the OPs, or the increase in the solubility parameter of the solvent blend produces the particle size decrease. The linear correlation could be only observed in batches prepared with the lowest polymer concentration (200 mg) either with PLGA $50: 50$ or Eudragit ${ }^{\circledR}$ E 100 and using $\leq 2 \%(w / v)$ of either PVA or P-407. For these system compositions, the prediction of the particle size can be achieved knowing the solubility parameter of the OP. This correlation between the solubility parameters of the solvent blends and the particle size in aqueous dispersion in the nanoscale inversely correlates with those results obtained by the other group [25] for microparticles in organic solvents as dispersion medium, using monomers and the dispersion polymerization method. Those results showed that bigger particles were obtained as the solubility parameter increased [25]. Thus, with the correlation found in this study, it could be hypothesized that the formation of the nanoparticles is given in the emulsification step, in which all the components are interacting. The water addition after the emulsification [1] or the solvent removal [8] steps were stated for particle formation by other methods.

From all the experimental designs, some results in common were found. Using the ratios of 75:25 of the solvent blends THF-EtAc, ACE-EtAc and ACE-MEK with PLGA or EtEtAc and ACE-EtAc with Eudragit ${ }^{\circledR}$ E100, similar and smallest particle sizes and PdIs could be obtained in this study. This could be due to the similarity of the solubility parameters of the solvents blends with the polymers (solubility parameter of Eudragit ${ }^{\circledR}$ E: 19.70 [37], and PLGA: 20.20 [32]) and the stabilizers (solubility parameter of PVA: 23.72 and P-407: 21.75 [37]). In contrast, using the solvent blend ACE-EtAc (50:50) as OP, and using either PLGA with P-407 at 5\% $(w / v)$ or Eudragit ${ }^{\circledR}$ E100 at $800 \mathrm{mg}$, the most unstable and polydispersed systems were produced with particle sizes in the microscale (Table 3, Experimental design 2, Figure 2c,f; Experimental design 10, Figure S2c,d of the Supplementary Material). In the same way, the lowest linear correlations were found with these systems. It could be explained because the high polymer concentration (polymers/stabilizers) in those systems produced a decrease in the polymer-solvent interactions, increasing the polymer-polymer attraction forces, generating zones of polymeric chains in coiled conformation, unable to form monodispersions. Since the molecular mobility was restricted, the intermolecular friction increased, which could produce bigger particles. It is important to note that further studies must be done to analyze the correlation of the complete contribution of the solubility parameters of all components versus the particle size values to confirm the results obtained in this investigation. 
Table 5. Linear correlation data from Hansen solubility parameters of OPs versus nanoparticle size.

\begin{tabular}{|c|c|c|c|c|}
\hline Solvent Blend or OP & [Polymer] & [Stabilizer] \% $(w / v)$ & $\begin{array}{l}\text { Correlation Equation } \\
\text { for Particle Size }\end{array}$ & $\mathbf{r}^{2}$ \\
\hline $\begin{array}{l}\text { ACE-MEK }(0: 100 \text { to } 75: 25) \\
\text { THF-EtAc }(0: 100 \text { to } 75: 25)\end{array}$ & PLGA (50:50), $200 \mathrm{mg}$ & & $\begin{array}{l}y=-427.93 x+8556.4 \\
y=-157.57 x+3201.8\end{array}$ & $\begin{array}{l}0.8432 \\
0.7699\end{array}$ \\
\hline ACE-EtAc (0:100 to $75: 25)$ & $\begin{array}{l}\text { Eudragit }^{\circledR} \text { E100, } 200 \mathrm{mg} \\
\text { Eudragit }^{\circledR} \text { E100, } 400 \mathrm{mg} \\
\text { Eudragit } \\
\text { E100, } 800 \mathrm{mg}\end{array}$ & PVA $2 \%$ & $\begin{array}{l}y=-124.29 x+2590.2 \\
y=-130.23 x+2723.1 \\
y=8135.6 x-144,556\end{array}$ & $\begin{array}{l}0.8197 \\
0.2000 \\
0.0227\end{array}$ \\
\hline ACE-MEK (0:100 to $75: 25)$ & Eudragit $^{\circledR}$ E100, $400 \mathrm{mg}$ & & $y=-739.64 x+14,788$ & 0.1503 \\
\hline Et-EtAc (0:100 to $75: 25)$ & Eudragit ${ }^{\circledR}$ E100, $200 \mathrm{mg}$ & $\begin{array}{l}\text { PVA 1\% } \\
\text { PVA 2\% } \\
\text { PVA 5\% } \\
\text { P-407 1\% } \\
\text { P-407 2\% } \\
\text { P-407 5\% }\end{array}$ & $\begin{array}{c}y=-2.7458 x+238.35 \\
y=-20.285 x+642.2 \\
y=-7.8519 x+338.56 \\
y=-35.846 x+917.08 \\
y=-26.586 x+726.96 \\
y=-64.851 x+1686.3\end{array}$ & $\begin{array}{l}0.0281 \\
0.9037 \\
0.1376 \\
0.9016 \\
0.3481 \\
0.2465\end{array}$ \\
\hline
\end{tabular}

All systems were prepared with an OP: $20 \mathrm{~mL}$ and an AP: $40 \mathrm{~mL} ;(n=3){ }^{\text {a }}$ The general linear equation is $y=m x+b$ where $y$ is the particle size for a solubility parameter given $(x)$.

Regarding the yield, it was apparently affected by the high vapor pressure and low boiling point of the solvents, particularly when acetone (boiling point: $56.2{ }^{\circ} \mathrm{C}$ and vapor pressure: $240 \mathrm{hPa}$ at $20^{\circ} \mathrm{C}$ [38]) was used. This solvent diffused quickly to the external phase and its evaporation led to instability and fast precipitation, as many microparticles were seen adhered to the walls of the container.

3.2.2. Effect of the Composition of Solvent Blend and Its OP Ratio on Zeta Potential and $\mathrm{pH}$

Acid dissociation constants or $\mathrm{pK}_{\mathrm{a}}$ values usually are used to analyze and compare the deprotonation state of molecules in aqueous systems [39]. The acid dissociation constant measures the strength of an acid in a solution influencing consequently their solubility. The acid will be stronger as the $\mathrm{pK}_{\mathrm{a}}$ values decrease [40]. However, this definition cannot be applied using organic solvents and their mixtures with water and other polymers. In this regard, there is still a largely uncharted territory about these complex systems [41].

Analyzing the nanoparticles prepared with the polymer PLGA (50:50), PVA at 2\% $(w / v)$ and THF-EtAc, significantly more neutral absolute values of zeta potential $(\leq 2 \mathrm{mV})$ were observed $(p<0.05)$ compared with the solvent blend ACE-MEK (Table 3, Experimental design 1; Figure 1c). One explanation to this behavior could be given due to the partial protonation of PLGA $\left(\mathrm{pK}_{\mathrm{a}}=3.85\right)$ produced using $100 \%(v / v)$ of MEK compared with EtAc. It could be hypothesized that more ionized carboxyl groups of the polymer produced a significant lower absolute value of zeta potential. These results are in agreement with those reported previously using PLGA [42], in which the zeta potential of the particles $(\sim 1.6 \mu \mathrm{m})$ was highly negative at $\mathrm{pH} 7.4$, and almost zero as $\mathrm{pH}$ decreased to 3.0. Nonetheless, this significant difference was only observed for PLGA with carboxyl groups ends, contrasting with the results in this study in which PLGA ester ends was utilized. The increasing addition of ACE into the OP produced even more neutral zeta potential values compared with the addition of THF in this study. This effect to obtain more neutral zeta potential values was more evident using PLGA 50:50, P-407 at 1\% (w/v) and ACE-MEK compared with ACE-EtAc (Table 3, Experimental design 11, Figure 7d). This tendency was not observed using the same polymer with a higher concentration of P-407 $(5 \% w / v)$, probably due to the thicker layer of the stabilizer around the particle charge (Experimental design 10, Figure $7 \mathrm{~b}$ ).

In the same way, a similar behavior was found when Eudragit ${ }^{\circledR}$ E100 was used in solvent blends consisting of either ACE-EtAc (Table 3, Experimental design 2 and 3; Figures 1-3), Et-EtAc (Table 3, Experimental design 3 and 4; Figures 1, 4 and 5), or ACE-MEK (Table 3, Experimental design 6; Figure 6(b3)). Zeta potential decreased as the ratio of the 
partially water-miscible solvent into the organic phases decreased and simultaneously the water-miscible solvent increased, but they were enough high to provide physical stability (Figures 1-6). In this case, the polymer Eudragit ${ }^{\circledR}$ E100, based on dimethylaminoethyl methacrylate and neutral methacrylic acid esters with a pKa of 7.0-7.3 [43], is soluble at pH 5 and swellable/permeable or partially protonated above of this value [44]. Thus, the same hypothesis could be given relating the partial polymer ionization in the systems (solvents, polymers and water) with more acidic properties, especially when the solvent blends of Et-EtAc or ACE-EtAc were used as OPs at low polymer concentrations (200 mg) [45-47]. This effect could be observed using either PVA or P-407 as stabilizers but was not so clear using a higher polymer concentration (Table 3, design 6; Figure 6). Further studies need to be done regarding this hypothesis.

The $\mathrm{pH}$ of the final aqueous dispersion of NPs (after the solvent evaporation step) was measured showing higher $\mathrm{pH}$ values than the $\mathrm{pK}_{\mathrm{a}}=3.85$ of PLGA and more neutral zeta potential values using the solvent blend ACE-MEK or increasing the ratio of the watermiscible solvent into the OP (Table 3, Experimental design 11, Figure 7e). This suggests a higher partial ionization of the polymer molecules in these systems [45-47]. As PLGA is an acid, more ionized carboxyl groups of the polymer are produced at a $\mathrm{pH}$ above of its $\mathrm{pK}_{\mathrm{a}}$, in which $50 \%$ of the polymeric molecules are ionized.

On the other hand, batches prepared with Eudragit ${ }^{\circledR}$ E 100 and the solvent blend Et-EtAc (Table 3, Experimental design 4) shown higher $\mathrm{pH}$ values of the final NPs aqueous dispersions as the partially water-miscible solvent decreased its ratio into the OP (Et:EtAc $\mathrm{pH}$ at $0: 100=6.83,25: 75=7.00,50: 50=7.52$ and 75:25 =7.46). The $\mathrm{pH}$ increasing and the lowering the NPs zeta potential, indicates a higher solubility of Eudragit ${ }^{\circledR}$ E 100 (which behaves as a $\mathrm{pH}$ modifier to increase the microenvironment $\mathrm{pH}$ as a weak base [48]). Opposite results were observed with a neutral poly- $\varepsilon$-caprolactone using the emulsificationdiffusion method [2]. As different molecular arrangements can be obtained by changing the nature of the solvent [49], it could also be hypothesized that at higher ratios of ethanol (dielectric constant: 24 at $25{ }^{\circ} \mathrm{C}$ [38]) into the solvent blend Et-EtAc, more polar parts of the polymer could be located near the water-polymer interface, and few alkyl chains could be positioned facing the external phase where the EtAc, of hydrophobic nature (EtAc dielectric constant: 6.27 at $\left.20^{\circ} \mathrm{C}[50]\right)$, could be displaced.

\subsubsection{Effect of the Stirring Rate on Particle Size and PdI}

The production of particle sizes below $1000 \mathrm{~nm}$ with low PdIs could be obtained using a minimum stirring rate of $1500 \mathrm{rpm}$ with a mechanical stirrer (Table 3, experimental design 5 , Figure 6(a1,a2)). Stirring rates below of this value and using magnetic stirring produce polydispersions in the nanoscale and the microscale (Table 2). Using a high-performance dispersing machine at $8000 \mathrm{rpm}$, narrower and more controlled particle size distributions were obtained compared with those produced using mechanical stirring with a 4-bladed dispersing propeller (Table 3, design 1, Figure 1a,b).

\subsubsection{Effect of the Polymer Concentration on Particle Size, PdI and Zeta Potential}

Comparing the results obtained using higher polymer concentrations, no significant differences or trends on particle sizes were found, except when EtAc was used alone. However, higher PdI indexes and zeta potential values $(p<0.05)$ were found increasing the Eudragit ${ }^{\circledR}$ E100 concentration at $4 \%(w / v$, Table 3, design 2, Figures 2 and 3). In general, a higher robustness can be achieved by using this modification compared with the standard emulsification-diffusion method, in which particle size increased using a polymer concentration above $2.5 \%(w / v)$ [2]. Nevertheless, a high variation in the data was observed in batches using $4 \%(w / v)$ of the polymer in this study, probably due to the poor solvent diffusion affected by a higher viscosity of the OP. This restricted solvent diffusion could produce an Ostwald ripening phenomenon in the emulsion, but not enough to increase the particle size as it is reported for the emulsification-diffusion [2] and emulsificationevaporation [17] methods. 


\subsubsection{Effect of the Stabilizers and Their Concentration on Particle Size and PdI}

Analyzing the results of particle size by using Eudragit ${ }^{\circledR}$ E 100 (200 mg), PVA and P-407 at 2-5\% $(w / v)$, noticeable differences were observed. The higher particle sizes were found by using higher ratios of the partially water-miscible solvent EtAc into the OPs compared with its lower ratios, but no trends were found. When an OP ratio of 25:75 or 75:25 was used, a tendency to increase the particle size was found as P-407 concentration increased. On the other hand, the use of PVA produced significant higher particles sizes $(p<0.05)$ at higher ratios of the water-miscible solvent into the OP, compared with those using P-407 at all stabilizer concentrations. Additionally, a slightly tendency by using PVA to decrease the particle size was found, by increasing the water-miscible solvent ratio into the OP (Experimental design 4, Table 3, Figures 4a-d and 5a). The same behavior was found for the PdIs, when higher values were obtained as the PVA or P-407 concentration and partially water-miscible solvent into the OP increased (Experimental design 4, Table 3, Figures $4 \mathrm{e}$ and $5 b$ ).

Increasing the Eudragit ${ }^{\circledR}$ E 100 concentration at $400 \mathrm{mg}$ and using MEK at $100 \%$ $(v / v)$, an evident decrease in the particle size and PdI $(p<0.05)$ was found by using PVA at 2 instead of $1 \%(w / v$, Table 3, design 8, Figure 6(d1,d2)). Similar results were found using the emulsification-diffusion [1,51-53] and a modified emulsion-solvent evaporation process [17], suggesting that more stabilizer molecules can be placed in the o/w interface decreasing the interfacial tension.

A better performance to obtain the smallest sizes either with Eudragit ${ }^{\circledR}$ E100 $(\sim 50 \mathrm{~nm})$ or with PLGA (50:50, 145 nm) was found using P-407 as stabilizer at low concentrations $(1 \%, w / v)$, and decreasing the ratio of the partially miscible solvent into the OP, compared with PVA in all the concentration range $(1-5 \% w / v$; Table 3, Experimental design 12, Figure 7f). Nonetheless, similar particles sizes were found with PLGA (50:50) and P-407 S 1\% ( w/v; Table 3, Experimental design 9; Figure S2a,b of the Supplementary Material). Contrarily, the highest sizes and PdIs were found using higher concentrations of P-407 and higher ratios of the partially water-miscible solvent into the OP using either Eudragit ${ }^{\circledR}$ E100 or PLGA (50:50; Table 3, Experimental design 10; Figure S2c,d of the Supplementary Material). One explanation for this behavior is the ability of P-407 (critical micelle concentration of $2.8 \times 10^{-6} \mathrm{M}$ ) to form monomolecular micelles at low concentrations $\left(10^{-4}-10^{-5} \%\right)$, while at higher concentrations, multimolecular aggregates are formed with its hydrophilic polyoxyethylene chains facing the aqueous phases and creating a hydrophobic core $[54,55]$. The results obtained in this study contrast with the performance of stabilizers (PVA $>$ Poloxamers $>$ Polysorbate $80>$ SDS $=$ DTAB) observed to decrease in the particle size by emulsification-diffusion method [56], probably due to the low polymer concentration used in this study. Additionally, using P-407 as stabilizer, more physically stable systems with apparently higher yields were obtained compared with those using PVA, in which many particles remained adhered to the container walls at the end of the manufacture process.

The successful production of stable NPs at low stabilizer concentrations provides the advantage of avoiding their post-purification, reducing the toxicity and consequently their time processing.

\subsubsection{Effect of the Stabilizers and Their Concentration on Zeta Potential and $\mathrm{pH}$}

Stabilizers in this study were non-ionic, providing a steric stabilization effect between the NPs. Significant lower absolute values of zeta potential $(p<0.05)$ were obtained when their concentration increased (Table 3, Experimental design 4, Figures $4 \mathrm{f}$ and 5c; Experimental design 8, Figure 6(d3); Experimental design 9, Figure 7a). This behavior has also been reported for NPs of PLGA by emulsification-diffusion [2], and by a modified emulsion-solvent evaporation process [17].

A pattern to decrease the zeta potential was also observed when P-407 at $(1-5 \%$ w/v) and Eudragit ${ }^{\circledR}$ E100 at $200 \mathrm{mg}$ were utilized increasing the water-miscible solvent in the OP. Using $400 \mathrm{mg}$ of Eudragit ${ }^{\circledR}$ E 100, the effect was more noticeable. On the other hand, 
when PLGA (50:50) was used, this effect could even be observed at stabilizer concentrations below $1 \%(w / v)$. This suggests that the stabilizer is adsorbed on the solvent-water interface in the course of the emulsification step to form the droplets, whereas the remaining quantity prevents the particle aggregation [2]. This remaining quantity could produce a dense steric barrier masking the polymer charge and reducing the electrical behavior of the particles [57]. In addition, a higher $\mathrm{pH}(p<0.05)$ of the aqueous nanoparticle dispersion prepared with PLGA and PVA was obtained, compared with P-407, indicating a higher partial ionization of the molecules from the PLGA or a partial hydrolysis of PVA acetate group in the lightly acidic medium [58].

3.2.7. Effect of the Addition Order of the OP and AP in the Emulsification Step on the Size and Zeta Potential

Finally, smaller sizes $(\leq 200 \mathrm{~nm})$ and PdI indexes $(\leq 0.2)$ were found adding the OP into the AP to form an emulsion $\mathrm{O} / \mathrm{W}$ compared to the inverse order. The phase inversion from an emulsion $\mathrm{W} / \mathrm{O}$ to change for one $\mathrm{O} / \mathrm{W}$ could produce a higher instability in the droplets $\mathrm{O} / \mathrm{W}$ in the emulsification step, probably due to a faster evaporation of the OP by the stirring rate, producing bigger particle sizes (Table 3, design 7, Figure 6(c1-c3)). Zeta potential results are in agreement with the explanation given above.

Nanoparticles of $50 \leq 1000 \mathrm{~nm}$ could be successfully produced by a rapid emulsiondiffusion method using feasible operating conditions and equipment. A useful linear correlation between the particle size and the solubility parameter was found. Nonetheless, further studies must be performed to analyze the correlation of all solubility parameters from each formulation component versus the particle size to confirm the results obtained in this investigation. In addition, studies to entrap drugs in these NPs and to confirm their particle size, as well as to know their shape, texture, and structure need to be achieved to confirm its feasibility.

\section{Conclusions}

A rapid emulsion-diffusion method to broadly prepare polymeric nanoparticles by using safe materials and solvent blends (miscible/partially miscible in water, 25-100\%) as OPs is presented. No previous mutual organic/aqueous phase saturation and no water addition after the emulsification step were required. Emulsification of the OP dropwise addition into the AP or vice versa using low-high shear stirring produced unimodal nanoparticle distributions. An important linear correlation was found to predict the particle size from the OP solubility parameters. The decrease in the partially water-miscible solvent ratio or its polarity when they were used at $100 \%(v / v)$, or lowering the P-407 concentrations; or the increase in the OP polarity or concentrations of PVA produced smaller sizes and PdIs using either Eudragit ${ }^{\circledR}$ E 100 or PLGA (50:50). The smallest ( 50 nm) and highest sizes ( $\geq 600 \mathrm{~nm}$ ) and PdIs were obtained using P-407 compared with the use of PVA. Absolute values of zeta potential decreased when the water-miscible solvent in the OP or stabilizer concentration increased. An understanding of the influence on the formulation and processing parameters is given to feasibly produce NPs using simple equipment and safe materials. More studies should be conducted entrapping drugs.

Supplementary Materials: The following are available online at https: / www.mdpi.com/article/10 .3390/nano12020229/s1, Figure S1: (a) Batches showing the particle size versus PdI and (b) particle size versus the zeta potential in the optimization of the biodegradable NPs (PLGA 85:15 and 50:50 according to Table 2) of using different variables reported in Table 2. Bars error $=\mathrm{SD}, n=3$; Figure S2: Influence of P-407 at three low concentrations using ACE-MEK (75:25) on (a) the particle size and (b) PdI (Experimental design 9). Effect of ACE-EtAc at two ratios on the (c) particle size and (d) PdI, using P-407 5\% ( $w / v$; Experimental design 10). Influence of two solvent blends, as OP, at two ratios on the (e) PdI, by using P-407 1\% as stabilizer (Experimental design 11). Analysis of the effect of P-407 and PVA at $1 \%$ on the (f) PdI, using the solvent blend ACE-MEK (75:25), Experimental design 12. All batches were prepared with $200 \mathrm{mg}$ of PLGA (50:50), $2000 \mathrm{rpm}$, and a ratio of OP:AP (1:2), $n=3$. All 
the means bars correspond to the Bonferroni interval at the $95.0 \%$ confidence level. Table S1. Particle size, Zeta potential and PdI of all batches prepared at different formulation and operating conditions.

Author Contributions: All authors contributed to this study. Material preparation, data collection, analysis and investigation were performed by C.L.D.-D., Z.A., G.A.-M. and B.W. The first draft of the manuscript was written by C.L.D.-D. Supervising of the research, reviewing and editing of the manuscript was performed by H.D.C.S. All authors have read and agreed to the published version of the manuscript.

Funding: This research received financial support from ConTex and the Universidad Nacional Autónoma de México (UNAM).

Acknowledgments: The authors acknowledge to the Division of Molecular Pharmaceutics and Drug Delivery of the College of Pharmacy, The University of Texas at Austin for providing the materials and facilities to performance this study.

Conflicts of Interest: The authors declare no conflict of interest.

\section{References}

1. Leroux, J.C.; Allemann, E.; Doelker, E.; Gurny, R. New approach for the preparation of nanoparticles by an emulsification-diffusion method. Eur. J. Pharm. Biopharm. 1995, 41, 14-18.

2. Mora-Huertas, C.E.; Fessi, H.; Elaissari, A. Influence of process and formulation parameters on the formation of submicron particles by solvent displacement and emulsification-diffusion methods critical comparison. Adv. Colloid Interface Sci. 2011, 163, 90-122. [CrossRef] [PubMed]

3. Crucho, C.I.C.; Barros, M.T. Polymeric nanoparticles: A study on the preparation variables and characterization methods. Mater. Sci. Eng. C 2017, 80, 771-784. [CrossRef] [PubMed]

4. Almoustafa, H.A.; Alshawsh, M.A.; Chik, Z. Technical aspects of preparing PEG-PLGA nanoparticles as carrier for chemotherapeutic agents by nanoprecipitation method. Int. J. Pharm. 2017, 533, 275-284. [CrossRef]

5. Krishnaswamy, K.; Orsat, V. Sustainable Delivery Systems through Green Nanotechnology. In Nano-and Microscale Drug Delivery Systems; Grumezescu, A.M., Ed.; Elsevier: Amsterdam, The Netherlands, 2017; pp. 17-32.

6. Allouche, J. Synthesis of organic and bioorganic nanoparticles: An overview of the preparation methods. In Nanomaterials: A Danger or a Promise? A Chemical and Biological Perspective; Springer: London, UK, 2013; pp. 27-74.

7. Vanderhoff, J.W.; El-Aasser, M.S.; Ugelstad, J. Polymer Emulsification Process. U.S. Patent 4,177,177, 4 December 1979.

8. Quintanar-Guerrero, D.; Allémann, E.; Fessi, H.; Doelker, E. Pseudolatex preparation using a novel emulsion-diffusion process involving direct displacement of partially water-miscible solvents by distillation. Int. J. Pharm. 1999, 188, 155-164. [CrossRef]

9. Trotta, M.; Debernardi, F.; Caputo, O. Preparation of solid lipid nanoparticles by a solvent emulsification-diffusion technique. Int. J. Pharm. 2003, 257, 153-160. [CrossRef]

10. Hariharan, S.; Bhardwaj, V.; Bala, I.; Sitterberg, J.; Bakowsky, U.; Ravi Kumar, M.N. Design of estradiol loaded PLGA nanoparticulate formulations: A potential oral delivery system for hormone therapy. Pharm. Res. 2006, 23, 184-195. [CrossRef]

11. Sahana, D.K.; Mittal, G.; Bhardwaj, V.; Kumar, M.N.V.R. PLGA nanoparticles for oral delivery of hydrophobic drugs: Influence of organic solvent on nanoparticle formation and release behavior in vitro and in vivo using estradiol as a model drug. J. Pharm. Sci. 2008, 97, 1530-1542. [CrossRef] [PubMed]

12. Jain, A.K.; Swarnakar, N.K.; Godugu, C.; Singh, R.P.; Jain, S. The effect of the oral administration of polymeric nanoparticles on the efficacy and toxicity of tamoxifen. Biomaterials 2011, 32, 503-515. [CrossRef] [PubMed]

13. Galindo-Pérez, M.J.; Quintanar-Guerrero, D.; Cornejo-Villegas, M.d.1.Á.; Zambrano-Zaragoza, M.d.l.L. Optimization of the emulsification-diffusion method using ultrasound to prepare nanocapsules of different food-core oils. LWT 2018, 87, 333-341. [CrossRef]

14. Chen, C.; Yang, W.; Wang, D.T.; Chen, C.L.; Zhuang, Q.Y.; Kong, X.D. A modified spontaneous emulsification solvent diffusion method for the preparation of curcumin-loaded PLGA nanoparticles with enhanced in vitro anti-tumor activity. Front. Mater. Sci. 2014, 8, 332-342. [CrossRef]

15. Cheerarot, O.; Baimark, Y. Biodegradable silk fibroin/chitosan blend microparticles prepared by emulsification-diffusion method. e-Polymers 2015, 15, 67. [CrossRef]

16. Mainardes, R.M.; Evangelista, R.C. Praziquantel-loaded PLGA nanoparticles: Preparation and characterization. J. Microencapsul. 2005, 22, 13-24. [CrossRef]

17. Manchanda, R.; Fernandez-Fernandez, A.; Nagesetti, A.; McGoron, A.J. Preparation and characterization of a polymeric (PLGA) nanoparticulate drug delivery system with simultaneous incorporation of chemotherapeutic and thermo-optical agents. Colloids Surf. B Biointerfaces 2010, 75, 260-267. [CrossRef]

18. Poletto, F.S.; Fiel, L.A.; Donida, B.; Ré, M.I.; Guterres, S.S.; Pohlmann, A.R. Controlling the size of poly (hydroxybutyrate-cohydroxyvalerate) nanoparticles prepared by emulsification-diffusion technique using ethanol as surface agent. Colloids Surf. A Physicochem. Eng. Asp. 2008, 324, 105-112. [CrossRef] 
19. USPC. United States Pharmacopeia and National Formulary (USP43-NF38); United States Pharmacopeial Convention: Rockville, MD, USA, 2021; p. 6712.

20. Singh-Joy, S.D.; McLain, V.C. Safety assessment of poloxamers 101, 105, 108, 122, 123, 124, 181, 182, 183, 184, 185, 188, 212, 215, $217,231,234,235,237,238,282,284,288,331,333,334,335,338,401,402,403$, and 407, poloxamer 105 benzoate, and poloxamer 182 dibenzoate as used in cosmetics. Int. J. Toxicol. 2008, 27, 93-128.

21. FDA. Inactive Ingredient Database, 2021st ed.; FDA/Center for Drug Evaluation and Research: Silver Spring, MD, USA, 2021.

22. Süß, S.; Sobisch, T.; Peukert, W.; Lerche, D.; Segets, D. Determination of Hansen parameters for particles: A standardized routine based on analytical centrifugation. Adv. Powder Technol. 2018, 29, 1550-1561. [CrossRef]

23. Gårdebjer, S.; Andersson, M.; Engström, J.; Restorp, P.; Persson, M.; Larsson, A. Using Hansen solubility parameters to predict the dispersion of nanoparticles in polymeric films. Polym. Chem. 2016, 7, 1756-1764. [CrossRef]

24. Fujiwara, N.; Nishida, T.; Yamamoto, H. Adaptation of Hansen solubility parameter in evaluating transparency of composite materials. Heliyon 2019, 5, e02833. [CrossRef]

25. Shah, D.O. Surfactant Science Series. In Fine Particles: Synthesis, Characterization, and Mechanisms of Growth; Sugimoto, T., Ed.; Springer Nature: Cham, Switzerland, 2002; Volume 92, p. 179.

26. Li, Z.; Tao, W.; Zhang, D.; Wu, C.; Song, B.; Wang, S.; Wang, T.; Hu, M.; Liu, X.; Wang, Y.; et al. The studies of PLGA nanoparticles loading atorvastatin calcium for oral administration in vitro and in vivo. Asian J. Pharm. Sci. 2017, 12, 285-291. [CrossRef]

27. Birnbaum, D.T.; Kosmala, J.D.; Henthorn, D.B.; Brannon-Peppas, L. Controlled release of beta-estradiol from PLAGA microparticles: The effect of organic phase solvent on encapsulation and release. J. Control Release 2000, 65, 375-387. [CrossRef]

28. Makadia, H.K.; Siegel, S.J. Poly Lactic-co-Glycolic Acid (PLGA) as Biodegradable Controlled Drug Delivery Carrier. Polymers 2011, 3, 1377-1397. [CrossRef]

29. Huggins, M.L. The Solubility of Nonelectrolytes. By Joel H. Hildebrand and Robert S. Scott. J. Phys. Chem. 1951, 55, 619-620. [CrossRef]

30. Hansen, C.M. Hansen Solubility Parameters: A User's Handbook, 2nd ed.; CRC Press: Boca Raton, FL, USA, 2007.

31. Van Krevelen, D.W.; Te Nijenhuis, K. (Eds.) Comprehensive Tables. In Properties of Polymers, 4th ed.; Elsevier: Amsterdam, The Netherlands, 2009; pp. 889-953.

32. Madsen, C.G.; Skov, A.; Baldursdottir, S.; Rades, T.; Jorgensen, L.; Medlicott, N.J. Simple measurements for prediction of drug release from polymer matrices-Solubility parameters and intrinsic viscosity. Eur. J. Pharm. BioPharm. 2015, 92, 1-7. [CrossRef]

33. Reichardt, C.; Welton, T. (Eds.) Appendix A. Properties, Purification, and Use of Organic Solvents. In Solvents and Solvent Effects in Organic Chemistry, 4th ed.; Wiley-VCH: Weinheim, Germany, 2011; pp. 549-586.

34. Reichardt, C.; Welton, T. (Eds.) Empirical Parameters of Solvent Polarity. In Solvents and Solvent Effects in Organic Chemistry; Wiley-VCH: Weinheim, Germany, 2010; pp. 425-508.

35. Wongsawa, T.; Koonsang, T.; Kunthakudee, N.; Prapasawat, T.; Maneeintr, K.; Pancharoen, U. The experimental investigations on viscosity, surface tension, interfacial tension and solubility of the binary and ternary systems for tributyl phosphate (TBP) extractant in various organic solvents with water: Thermodynamic NRTL model and molecular interaction approach. J. Mol. Liq. 2018, 251, 229-237.

36. Yaws, C.L.; Richmond, P.C. Chapter 21-Surface tension-Organic compounds. In Thermophysical Properties of Chemicals and Hydrocarbons; Yaws, C.L., Ed.; William Andrew Publishing: Norwich, NY, USA, 2009; pp. 686-781.

37. Kitak, T.; Dumičić, A.; Planinšek, O.; Šibanc, R.; Srčič, S. Determination of Solubility Parameters of Ibuprofen and Ibuprofen Lysinate. Molecules 2015, 20, 21549-21568. [CrossRef]

38. Smallwood, I.M. (Ed.) Front Matter. In Handbook of Organic Solvent Properties; Butterworth-Heinemann: Oxford, UK, 1996; pp. $1-326$.

39. Rossini, E.; Bochevarov, A.D.; Knapp, E.W. Empirical Conversion of pK (a) Values between Different Solvents and Interpretation of the Parameters: Application to Water, Acetonitrile, Dimethyl Sulfoxide, and Methanol. ACS Omega 2018, 3, 1653-1662. [CrossRef] [PubMed]

40. Manallack, D.T.; Prankerd, R.J.; Yuriev, E.; Oprea, T.I.; Chalmers, D.K. The significance of acid/base properties in drug discovery. Chem. Soc. Rev. 2013, 42, 485-496. [CrossRef]

41. Radtke, V.; Stoica, D.; Leito, I.; Camões, F.; Krossing, I.; Anes, B.; Roziková, M.; Deleebeeck, L.; Veltzé, S.; Näykki, T.; et al. A unified $\mathrm{pH}$ scale for all solvents: Part I-intention and reasoning (IUPAC Technical Report). Pure Appl. Chem. 2021, 93, 1049-1060. [CrossRef]

42. Yoo, J.W.; Mitragotri, S. Polymer particles that switch shape in response to a stimulus. Proc. Natl. Acad. Sci. USA 2010, 107, 11205-11210. [CrossRef]

43. Moustafine, R.I.; Salachova, A.R.; Frolova, E.S.; Kemenova, V.A.; Van den Mooter, G. Interpolyelectrolyte complexes of Eudragit E PO with sodium alginate as potential carriers for colonic drug delivery: Monitoring of structural transformation and composition changes during swellability and release evaluating. Drug. Dev. Ind. Pharm. 2009, 35, 1439-1451. [CrossRef]

44. Patra, C.N.; Priya, R.; Swain, S.; Kumar Jena, G.; Panigrahi, K.C.; Ghose, D. Pharmaceutical significance of Eudragit: A review. Future J. Pharm. Sci. 2017, 3, 33-45. [CrossRef]

45. Serjeant, E.P.; Dempsey, B. Ionization Constants of Organic Acids in Aqueous Solution; Pergamon Press: Oxford, UK, 1979.

46. Kim, H.; Babu, C.R.; Burgess, D.J. Quantification of protonation in organic solvents using solution NMR spectroscopy: Implication in salt formation. Int. J. Pharm. 2013, 448, 123-131. [CrossRef] 
47. Wypych, G.A. (Ed.) 3.7-Generic Solvents. In Databook of Green Solvents; ChemTech Publishing: Toronto, ON, Canada, 2019; pp. 237-402.

48. Rao, V.M.; Engh, K.; Qiu, Y. Design of pH-independent controlled release matrix tablets for acidic drugs. Int. J. Pharm. 2003, 252, 81-86. [CrossRef]

49. Tang, Z.G.; Black, R.A.; Curran, J.M.; Hunt, J.A.; Rhodes, N.P.; Williams, D.F. Surface properties and biocompatibility of solvent-cast poly[-caprolactone] films. Biomaterials 2004, 25, 4741-4748. [CrossRef] [PubMed]

50. Van Krevelen, D.W.; Te Nijenhuis, K. (Eds.) Chapter 11-Electrical Properties. In Properties of Polymers, 4th ed.; Elsevier: Amsterdam, The Netherlands, 2009; pp. 319-354.

51. Kwon, H.Y.; Lee, J.Y.; Choi, S.W.; Jang, Y.; Kim, J.H. Preparation of PLGA nanoparticles containing estrogen by emulsificationdiffusion method. Colloids Surf. A Physicochem. Eng. Asp. 2001, 182, 123-130. [CrossRef]

52. Galindo-Rodríguez, S.A.; Puel, F.; Briançon, S.; Allémann, E.; Doelker, E.; Fessi, H. Comparative scale-up of three methods for producing ibuprofen-loaded nanoparticles. Eur. J. Pharm. Sci. 2005, 25, 357-367. [CrossRef]

53. Song, K.C.; Lee, H.S.; Choung, I.Y.; Cho, K.I.; Ahn, Y.; Choi, E.J.J.C.; Physicochemical, S.A.; Aspects, E. The effect of type of organic phase solvents on the particle size of poly (d, 1-lactide-co-glycolide) nanoparticles. Colloids Surf. A Physicochem. Eng. Asp. 2006, 276, 162-167. [CrossRef]

54. Suksiriworapong, J.; Rungvimolsin, T.; Agomol, A.; Junyaprasert, V.B.; Chantasart, D. Development and characterization of lyophilized diazepam-loaded polymeric micelles. AAPS PharmSciTech 2014, 15, 52-64. [CrossRef]

55. Domínguez-Delgado, C.; Fuentes-Prado, E.; Escobar-Chávez, J.; Vidal-Romero, G.; Rodríguez Cruz, I.; Díaz-Torres, R. Chitosan and Pluronic ${ }^{\circledR}$ F-127: Pharmaceutical Applications. In Encyclopedia of Biomedical Polymers and Polymeric Biomaterials; Mishra, M., Ed.; Taylor and Francis Group LLC: Boca Raton, FL, USA; London, UK; New York, NY, USA, 2016; pp. $1513-1535$.

56. Zhang, R.; Somasundaran, P. Advances in adsorption of surfactants and their mixtures at solid/solution interfaces. Adv. Colloid Interface Sci. 2006, 123, 213-229. [CrossRef]

57. Hirsjärvi, S.; Peltonen, L.; Hirvonen, J. Surface pressure measurements in particle interaction and stability studies of poly (lactic acid) nanoparticles. Int. J. Pharm. 2008, 348, 153-160. [CrossRef]

58. Fink, J.K. (Ed.) Chapter 2: Poly (vinyl alcohol). In Handbook of Engineering and Specialty Thermoplastics, Water Soluble Polymers; Scrivener Publishing LLC: Boston, MA, USA, 2011; Volume 2, pp. 39-68. 